\title{
Antimicrobial, Antioxidant, and Immunomodulatory Properties of Essential Oils: A Systematic Review
}

\author{
Magdalena Valdivieso-Ugarte ${ }^{1}$, Carolina Gomez-Llorente ${ }^{1,2,3,4, * \mathbb{C}}$, Julio Plaza-Díaz ${ }^{1,2,3}$ (I) and \\ Ángel Gil 1,2,3,4 (D) \\ 1 Institute of Nutrition and Food Technology “José Mataix", Center of Biomedical Research, University of \\ Granada, Avda. del Conocimiento s/n. 18016 Armilla, Granada, Spain; \\ malenavaldivieso@gmail.com (M.V.-U.); jrplaza@ugr.es (J.P.-D.); agil@ugr.es (Á.G.) \\ 2 Department of Biochemistry and Molecular Biology II, School of Pharmacy, University of Granada, \\ 18071 Granada, Spain \\ 3 ibs.GRANADA, Instituto de Investigación Biosanitaria, Complejo hospitalario Universitario de Granada, \\ 18014 Granada, Spain \\ 4 CIBEROBN (CIBER Physiopathology of Obesity and Nutrition), Instituto de Salud Carlos III, 28029 Madrid, \\ Spain \\ * Correspondence: gomezll@ugr.es; Tel.: +34-958-241-000 (ext. 40091)
}

Received: 31 October 2019; Accepted: 12 November 2019; Published: 15 November 2019

\begin{abstract}
Essential oils (EOs) are a mixture of natural, volatile, and aromatic compounds obtained from plants. In recent years, several studies have shown that some of their benefits can be attributed to their antimicrobial, antioxidant, anti-inflammatory, and also immunomodulatory properties. Therefore, EOs have been proposed as a natural alternative to antibiotics or for use in combination with antibiotics against multidrug-resistant bacteria in animal feed and food preservation. Most of the results come from in vitro and in vivo studies; however, very little is known about their use in clinical studies. A systematic and comprehensive literature search was conducted in PubMed, Embase ${ }^{\circledR}$, and Scopus from December 2014 to April 2019 using different combinations of the following keywords: essential oils, volatile oils, antimicrobial, antioxidant, immunomodulation, and microbiota. Some EOs have demonstrated their efficacy against several foodborne pathogens in vitro and model food systems; namely, the inhibition of S. aureus, V. cholerae, and C. albicans has been observed. EOs have shown remarkable antioxidant activities when used at a dose range of 0.01 to $10 \mathrm{mg} / \mathrm{mL}$ in cell models, which can be attributed to their richness in phenolic compounds. Moreover, selected EOs exhibit immunomodulatory activities that have been mainly attributed to their ability to modify the secretion of cytokines.
\end{abstract}

Keywords: essential oils; volatile oils; antimicrobial; antioxidant; immunomodulatory; food preservation; biofilm

\section{Introduction}

Foodborne-related diseases are an increasingly major public health problem worldwide [1]. Microbial contamination is one of the factors in developing foodborne diseases and food spoilage [2]. Since ancient times, different methods to preserve food for a longer period have been sought. For this reason, and thanks to the advancement of knowledge and the rapid development of new technologies, different chemical compounds have been developed, commonly known as additives, which extend the life of foods or are used as sweeteners or coloring agents [3]. however, the presence of pathogenic microorganisms continues to result in large economic losses and multiple diseases in humans [4]. On the other hand, the indiscriminate use of antibiotics in both humans and animals against pathogenic 
microorganisms has contributed to the extension of resistant and even multidrug-resistant bacterial strains $[4,5]$. In recent years, a tendency to use natural additives, mainly due to the increasing desire for the consumption of minimally processed products, has emerged $[4,6]$. Therefore, there is a need for alternative natural compounds that can perform the same function of common additives or can be used as an alternative to antibiotics. One such possibility is the use of essential oils (EOs) due to their known antimicrobial, antioxidant, immunomodulatory, and food preservative activities [7]. In line with this, several studies have described the antibacterial activity of EOs, underlying their effective use on multidrug-resistant strains $[8,9]$.

EOs, also known as "volatile oils", are complex mixtures of volatile compounds that are produced by aromatic plants as secondary metabolites. They are responsible for the aromatic plant's properties, and for this reason, they are characterized by their strong smells [10]. In general, EOs are liquid, volatile, and soluble in lipids and organic solvents. They can be present in all plant organs, including buds, flowers, leaves, seeds, stems, flowers, fruits, roots, wood, or bark. Different extraction techniques are widely employed for the extraction of EOs such as steam distillation, solvent extraction, and supercritical fluid extraction [11,12]. These EOs are characterized by the presence of variable mixtures of bioactive compounds, mainly terpenoids, especially monoterpenes and sesquiterpenes. Some of them also contain nonterpenic compounds biogenerated by the phenylpropanoid pathway, such as eugenol, cinnamaldehyde, and safrole [13]. These bioactive compounds are responsible for the biological properties of EOs. Among them, terpenoids are the bioactive compounds that have a more important role in pathogen resistance [14]. Specifically, monoterpenoids affect the multiplication and development of microorganisms by interfering with their physiological and biochemical processes during their development and multiplication [15]. Cinnamon bark oil is one of the most effective EOs against common foodborne pathogens [16]. It should be noted that the effect of EOs on bacterial growth will depend on whether they are Gram-positive or Gram-negative bacteria, since the lipopolysaccharide (LPS) layer in Gram-negative bacteria acts as a barrier for macromolecules and hydrophobic compounds such as those present in EOs [15]. Using EOs to extend the shelf life of fish and meat has also been reported in previous studies. Examples include the preservative effect of lemon EOs on salted sardines [17], the effect of chitosan coatings enriched with cinnamon oil on the quality of rainbow trout (Oncorhynchus mykiss) during refrigerated storage [18], and the lengthening of the storage period of red sea bass by means of clove, cumin, and peppermint oils or poultry meat in thyme oil [19].

The antioxidant activity of EOs is another biological property of great interest because they may preserve foods from the toxic effects of oxidants [20]. It is noteworthy to mention that EOs have also been shown to possess a wide range of immunomodulatory properties. To date, a few studies dealing with the immunomodulatory effect of EOs have been reported [21-23]. In this regard, monoterpenes have been shown to exert a strong immunobiological effect through their effect on tumor necrosis factor (TNF)- $\alpha$, interleukins (ILs), thromboxane, and leukotriene production [24]. This immunomodulatory activity indicated the possibility of using EOs as ingredients in functional foods.

Most of the results of the antimicrobial, antioxidant, and immunomodulatory effects of EOs come from in vitro and in vivo studies. however, very little is known about their use in clinical studies. The present work aims to perform a systematic review of the scientific literature on the important biological properties of EOs in food preservation and to describe the antimicrobial, antioxidant, and immunomodulatory properties that render them desirable for use in functional foods.

\section{Materials and Methods}

\subsection{Search Strategy}

In this review, the specialized databases PubMed (US National Library of Medicine National Institutes of health), Embase ${ }^{\circledR}$, and Scopus were used for the literature search from December 2014 to April 2019, with the aim of restricting the search to the articles that make use of the most modern techniques, using different combinations of the following keywords: essential oils, volatile 
oils, antimicrobial, antioxidant, immunomodulation, and microbiota. In PubMed, we used the following search equation strategy: ("essential oils" [All Fields] OR "volatile oils" [All Fields]) AND ("immunomodulation" [All Fields] OR "drug resistance, multiple, bacterial" [All Fields] OR "immune system" [All Fields]). When we used PubMed, we included Medical Subject heading (MeSH) terms to increase the power of the search. The search equation used in Scopus was: "essential AND oils" AND immunomodulation AND drug resistance, multiple, bacterial.

\subsection{Selection Criteria}

Articles were organized by the antimicrobial and immunomodulatory effects of EOs; after that, two members of the team (M.V.-U. and C.G.-Ll.) extracted information about the characteristics of the studies. The information extracted from the articles included EOs, cell lines (in vitro studies), animal models (in vivo studies), doses or concentrations, routes of administration, biochemical assays, and the molecular mechanisms investigated. The quality assessment and selection were performed by two authors (M.V.-U. and C.G.-Ll.) who independently worked according to the main criteria of PICO (Population, Intervention, Comparison, Outcome) (Table 1); in case of discrepancies, a third independent reviewer (J.P.-D.) was consulted for the final decision.

Table 1. PICO (Population, Intervention, Comparison, Outcome) criteria for inclusion of studies.

\begin{tabular}{cc}
\hline Parameter & Inclusion Criteria \\
\hline Population & Studies performed in cells and animals, including humans \\
Intervention & Treatment with essential oil \\
Comparison & Essential oil vs. control \\
Outcome & Antimicrobial, antioxidant, and immunomodulatory effects \\
\hline
\end{tabular}

\subsection{Data handling, Analyses, and Extraction}

The inclusion criteria used were the following: (1) studies with EOs with antimicrobial and immunomodulatory properties in vitro and in vivo; (2) food and nutrition-related studies; and (3) studies with significant results obtained through appropriate statistical analysis. The exclusion criteria used were as follows: (1) studies written in languages other than English or Spanish; (2) the use of plant extracts or derivatives, instead of EOs; (3) review articles, conference proceedings, and editorials/letters; (4) studies without controls; and (5) agar diffusion method as the only assay for the study of the antimicrobial effect. After removing duplicates, acceptability for inclusion was evaluated based on the following: (1) reading the title and abstract; and (2) reading the full text.

We provided a narrative synthesis of the main results of the selected articles. These results were classified according to the EOs' properties: (i) antimicrobial activity, (ii) antioxidant activity, and (iii) immunomodulatory effects of EOs in cells and animals.

\section{Results}

\subsection{Study Identification and Selection}

Seventy-nine relevant articles were identified, which was in agreement with our inclusion and exclusion criteria. The selected articles were grouped into the antimicrobial and antioxidant effects of the EOs, immunomodulatory effects of EOs in cell studies, and animal supplementation with EOs. We only found one article in human samples that met our eligibility criteria. We did not find any intervention studies in humans. The complete process is explained in Figure 1, which is based on a PRISMA flow chart. 


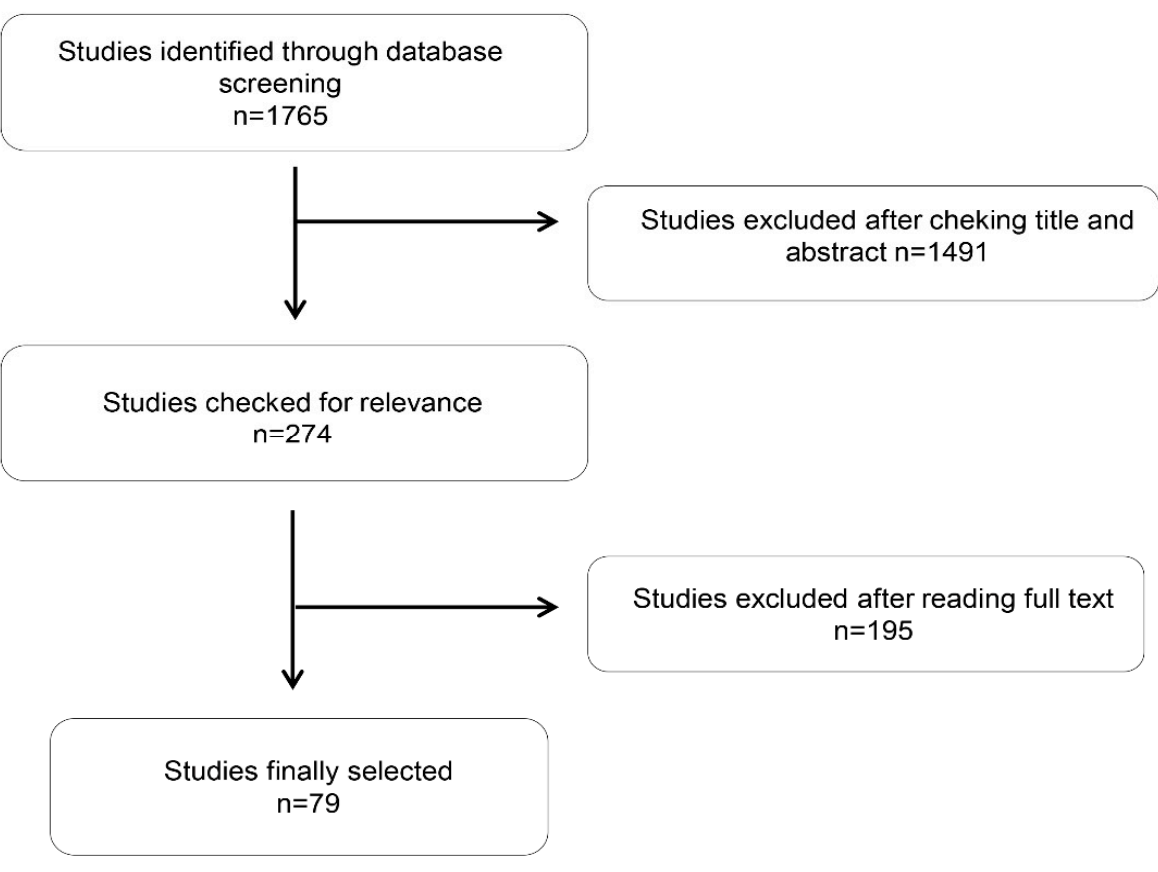

Figure 1. PRISMA flow chart for studies related with antibacterial, antioxidant, and immunomodulatory properties of essential oils.

\subsection{Antimicrobial Activity of Esential Oils}

Table 2 lists the selected publications and their main results of the antimicrobial effect of EOs. In total, 49 articles were identified. Forty-three articles described the effects of EOs over several bacterial strains such as E. coli, S. aureus, B. cereus, and P. aeruginosa. In six articles, the inhibition of biofilm formation by EOs was described. The dose used for the determination of minimum inhibitory concentration (MIC)/minimum bactericidal concentration (MBC) values ranged from 9 to $229 \mathrm{mg} / \mathrm{mL}$, and the incubation time varied from 18 to $24 \mathrm{~h}$.

\subsection{Antioxidant Activity of Essential Oils}

Table 3 depicts the articles and their main results regarding the antioxidant effects of EOs. Twenty-one studies were selected. The main methods used to evaluate the antioxidant capacity were the following: measuring 1,1-diphenyl-2-picrylhydrazyl (DPPH) and 2'-azino-bis(3-ethylbenzothiazoline-6-sulphonic acid) (ABTS) radicals scavenging activity, ferric-reducing antioxidant power (FRAP), and oxidative DNA damage protective effect induced by $\mathrm{Fe}^{2+}$ and 2,2'-azobis (2-methylpropionamidine) dihydrochloride (AAPH). EOs demonstrated ability in antioxidant assays in a concentration-dependent manner. The dose range was $0.05 \%$ to $3.2 \% v / w, 0.1$ to $10 \mathrm{mg} / \mathrm{mL}$, and 12.5 to $2000 \mu \mathrm{g} / \mathrm{mL}$.

\subsection{Immunomodulatory Activity of Essential Oils in Cells and Animals}

Tables 4 and 5 describe the main effects of EOs in cellular and animal studies, respectively. Eight of the selected studies were specifically conducted in cells, whereas five out of 14 publications selected performed antimicrobial studies against different bacterial strains and immunomodulatory studies in a cellular model. Most of the studies were conducted in animal cells (nine out of 13), although studies in human cells were also performed (seven out of 14). The dose ranged from 1.25 to $1000 \mu \mathrm{g} / \mathrm{mL}$, and the incubation times varied from 1 to $72 \mathrm{~h}$. In the case of animal studies, six out of 10 were performed on poultry animals, while three out of 10 were performed on C57BL/6 mice. One article was performed in silver catfish. The dose administrated varied from $7.5 \mathrm{mg} / \mathrm{kg}$ to $1 \mathrm{~kg} / \mathrm{ton}$ in weaned piglets. 
Table 2. Main characteristics of studies related with antibacterial properties of essential oils.

\begin{tabular}{|c|c|c|c|c|}
\hline Article & Plant Derived EOs & Main Components of EOs & Bacteria & $\mathrm{MIC} / \mathrm{MBC} / \mathrm{IC}_{50}$ \\
\hline $\begin{array}{c}\text { Aghraz et al. } \\
{[25]}\end{array}$ & $\begin{array}{l}\text { Cladanthus arabicus and } \\
\text { Bubonium imbricatum }\end{array}$ & $\begin{array}{c}\text { Cladanthus arabicus: oxygenated monoterpenes }(61.4 \%): \\
\text { cis-chrysanthenyl acetate (31.4\%) and thymolisobutyrate (3.4\%); } \\
\text { Bubonium imbricatum: monoterpenes hydrocarbons }(75.8 \%): \\
\text { sabinene }(31.1 \%), \beta \text {-pinene }(16.7 \%) \text {, myrcene }(12.3 \%), \text { and } \\
\alpha \text {-pinene }(5.3 \%)\end{array}$ & $\begin{array}{l}\text { E. coli, K. pneumoniae, E. cloacae, } \\
\text { P. mirabilis, Salmonella spp. }\end{array}$ & $\begin{array}{l}\text { MIC } 200-800 \mu \mathrm{g} / \mathrm{mL} \text { for C. arabicus, } \\
\text { MIC } 400-1600 \mu \mathrm{g} / \mathrm{mL} \text { for } \\
\text { B. imbricatum }\end{array}$ \\
\hline $\begin{array}{l}\text { Alarcon et al. } \\
{[26]}\end{array}$ & Ruilopezia bracteosa & $\begin{array}{c}\beta \text {-myrcene (34.2\%), } \alpha \text {-pinene (24.3\%), 7-epi- } \alpha \text {-selinene (9.1\%), } \\
\text { and } \beta \text {-pinene (8.5\%) }\end{array}$ & $\begin{array}{l}\text { S. aureus, E. faecalis, K. pneumoniae, } \\
\text { E. coli, S. Typhi, P. aeruginosa }\end{array}$ & MIC $10 \mu \mathrm{g} / \mathrm{mL}$ \\
\hline $\begin{array}{l}\text { Ashraf et al. } \\
{[27]}\end{array}$ & Nigella sativa & $\begin{array}{l}\text { hymoquinone, dithymoquinone, thymohydroquinone, and } \\
\text { thymol }\end{array}$ & $S$. Enterica & MIC $\geq 1000.0 \pm 322.7 \mu \mathrm{g} / \mathrm{mL}$ \\
\hline $\begin{array}{l}\text { Behbahani et al. } \\
\text { [28] }\end{array}$ & Oliveria decumbens & $\begin{array}{l}\text { Thymol }(28.45 \%) \gamma \text {-terpinene }(22.2 \%), \rho \text {-cymene }(17.90 \%) \text {, } \\
\text { myristicin }(13.55 \%) \text {, carvacrol }(8.50 \%) \text {, and limonene }(2.60 \%)\end{array}$ & $\begin{array}{l}\text { P. aerogenes, E. coli, S. pyogenes, } \\
\text { S. epidermidis }\end{array}$ & MIC, $1-8 \mathrm{mg} / \mathrm{mL} ; \mathrm{MBC} 1-16 \mathrm{mg} / \mathrm{mL}$ \\
\hline $\begin{array}{l}\text { Boonyanugomol } \\
\text { et al. } \\
\text { [29] }\end{array}$ & Zingiber cassumunar & $\begin{array}{l}\text { sabinene, } \gamma \text {-terpinene, } \alpha \text {-terpinene, terpinene- } 4 \text {-ol, and } \\
\text { (E)-1-(3,4-dimethoxyphenyl)butadiene }\end{array}$ & Acinetobacter baumannii & MIC/MBC: $7.00-9.24 \mathrm{mg} / \mathrm{mL}$ \\
\hline $\begin{array}{l}\text { Chaib et al. } \\
\text { [30] }\end{array}$ & $\begin{array}{l}\text { Asteriscus graveolens and } \\
\text { Pulicaria incisa }\end{array}$ & $\begin{array}{l}\text { Asteriscus graveolens: cis-chrysanthenyl acetate }(31.1 \%), \\
\text { myrtenyl acetate }(15.1 \%), \text { and kessane }(11.5 \%) ; \text { Pulicaria incisa: } \\
\text { chrysanthenone }(45.3 \%) \text { and } 2,6 \text {-dimethylphenol }(12.6 \%)\end{array}$ & $\begin{array}{l}\text { K. pneumoniae, E. coli, A. baumannii, } \\
\text { P. aeruginosa, L. monocytogenes, } \\
\text { S. aureus, P. mirabilis }\end{array}$ & MIC: $19-1250 \mu \mathrm{g} / \mathrm{mL}$ \\
\hline $\begin{array}{l}\text { Chen et al. } \\
\text { [31] }\end{array}$ & $\begin{array}{l}\text { Kunzea ericoides and } \\
\text { Leptospermum scoparium }\end{array}$ & - & $\begin{array}{l}\text { T. mucoides, C. tropicalis, S. aureus, } \\
\text { S. mutans, S. sobrinus, E. coli }\end{array}$ & MIC $0.78 \%-3.13 \%$ \\
\hline $\begin{array}{l}\text { Chiboub et al. } \\
\text { [32] }\end{array}$ & $\begin{array}{l}\text { Foeniculum vulgare MILL, } \\
\text { Daucus carota L. subsp. satious }\end{array}$ & $\begin{array}{c}\text { Daucus carota: isospathulenol, caryophyllene oxide, and } \\
\delta \text {-elemene } \\
\text { Foeniculum vulgare MILL: (E)-anethole p-anisaldehyde, } \\
\text { p-acetonylanisole, limonen, exo-fenchol acetate, and methyl } \\
\text { chavicol }\end{array}$ & $\begin{array}{l}\text { S. aureus, B. subtilis, } \\
\text { B. amyloliquefaciens, S. Enterica, E. coli, } \\
\text { C. albicans }\end{array}$ & MIC: $6.25-50 \mathrm{mg} / \mathrm{mL}$ \\
\hline $\begin{array}{l}\text { Condo et al. } \\
\text { [33] }\end{array}$ & $\begin{array}{l}\text { Pimpinella anisum } \mathrm{L} ., \\
\text { Cinnamomum zeylanicum, } \\
\text { Syzygium aromaticum, and } \\
\text { Cuminum cyminum } \mathrm{L} \text {. }\end{array}$ & $\begin{array}{c}\text { Pimpinella anisum L: trans-anethole ((E)-1-methoxy-4-(1-propenyl) } \\
\text { benzene); Cinnamomum zeylanicum: cinnamaldehyde; Syzygium } \\
\text { aromaticum: eugenol; Cuminum cyminum: cuminaldehyde } \\
\text { (4-isopropylbenzaldehyde), and cuminyl alcohol } \\
\text { (4-isopropyl-benzyl-alcohol) }\end{array}$ & $\begin{array}{l}\text { S. aureus, S. epidermidis, E. faecalis, } \\
\text { S. pyogenes, E. coli, P. aeruginosa, } \\
\text { A. hydrophila, P. mirabilis, } \\
\text { K. pneumoniae, C. albicans }\end{array}$ & \\
\hline $\begin{array}{l}\text { De Jesus et al. } \\
{[34]}\end{array}$ & Myrcia ovata Cambessedes & Geranial ( $40 \%)$, neral ( $28 \%)$, citronella $(9 \%)$ & $\begin{array}{l}\text { P. aeruginosa, S. aureus, B. cereus, } \\
\text { B. subtilis, E. faecalis, S. marcescens, } \\
\text { E. coli, S. enteritidis }\end{array}$ & MIC: $0.78-25 \mu \mathrm{L} / \mathrm{mL}$ \\
\hline $\begin{array}{l}\text { Elshafie et al. } \\
\quad[35]\end{array}$ & $\begin{array}{c}\text { Verbena officinalis, } \\
\text { Majorana hortensis, and Salvia } \\
\text { officinalis }\end{array}$ & $\begin{array}{c}\text { Verbena officinalis: Isobornyl formate (45.4\%), (E)-citral }(47.5 \%) \text {; } \\
\text { Majorana hortensis: 1,8-cineole (33.5\%), } \beta \text {-phellandrene }(9.1 \%), \\
\alpha \text {-pinene (9\%), limonene (6.4\%); Salvia officinalis: Trans-thurjone } \\
(37.9 \%) \text {, canfor }(13.9 \%) \text {, and borneol }(7.6 \%)\end{array}$ & $\begin{array}{l}\text { B. megaterium, B. mojavensis, } \\
\text { C. michiganensis, E. coli, X. campestris, } \\
\text { P. savastanoi, P. syringae pv. phaseolicola }\end{array}$ & MIC: $1000-10,000 \mathrm{mg} / \mathrm{L}$ \\
\hline
\end{tabular}


Table 2. Cont

\begin{tabular}{|c|c|c|c|c|}
\hline Article & Plant Derived EOs & Main Components of EOs & Bacteria & $\mathrm{MIC} / \mathrm{MBC} / \mathrm{IC}_{50}$ \\
\hline $\begin{array}{l}\text { Fadil et al. } \\
{[36]}\end{array}$ & $\begin{array}{l}\text { Mixture of Thymus vulgaris, } \\
\text { Rosmarinus officinalis L., and } \\
\text { Myrtus communis L. }\end{array}$ & $\begin{array}{c}\text { T. vulgaris: Thymol }(37.54 \%), \text { p-cymene }(14.49 \%) \text {, c-terpinene } \\
(11.15 \%), \text { linalool }(4.71 \%) \text {, and carvacrol }(4.62 \%) ; \\
\text { R. officinalis: } \alpha \text {-pinene }(48.58 \%), 1,8 \text {-cineole }(33.4 \%) \text { and camphene } \\
(8.69 \%) ; \text { M. communis: borneol }(27.15 \%), 1,8 \text {-cineole }(21.33 \%), \\
\alpha \text {-pinene }(11.09 \%) \text {, myrtenyl acetate }(6.45 \%) \text {, trans-pinocarveol } \\
(4.82 \%) \text {, and } \alpha \text {-terpineol }(4.83 \%)\end{array}$ & S. Typhimurium & $\begin{array}{l}\text { Thyme MIC: } 0.25 \%(V / V) \\
\text { myrtle MIC: } 0.5 \%(V / V) \\
\text { Rosemary MIC: } 2 \%(V / V)\end{array}$ \\
\hline $\begin{array}{l}\text { Falsafi et al. } \\
\text { [37] }\end{array}$ & Satureja bachtiarica Bunge & $\begin{array}{c}\text { Carvacrol (45.5\%), thymol }(27.9 \%), \text { p-cymene }(4.4 \%), \gamma \text {-terpinene } \\
(4.0 \%), \alpha \text {-pinene }(1.5 \%), 1,8 \text {-cineole }(1.3 \%), \alpha \text {-terpinene }(1.2 \%) \\
\text { and E-caryophyllene }(1.1 \%)\end{array}$ & H. pylori & MIC: $0.035 \mu \mathrm{L} / \mathrm{mL}$ \\
\hline $\begin{array}{l}\text { Fournomiti et al. } \\
{[38]}\end{array}$ & $\begin{array}{l}\text { Origanum vulgare, Salvia } \\
\text { officinalis, Thymus vulgaris }\end{array}$ & $\begin{array}{c}\text { Origanum vulgare: Carvacrol and thymol; Salvia officinalis: } \\
\text { 1,8-cineole, } \alpha \text {-thujone and camphor; Thymus vulgaris: thymol and } \\
\text { carvacrol }\end{array}$ & E. coli, K. oxytoca, K. pneumoniae & $\begin{array}{l}\text { MIC oregano: } 0.9 \mathrm{mg} / \mathrm{mL} ; 73.5 \mu \mathrm{g} / \mathrm{mL} \text {; } \\
\text { MIC thyme: } 8.1 \mu \mathrm{g} / \mathrm{mL} ; 9.5 \mu \mathrm{g} / \mathrm{mL} ; \\
28.6 \mu \mathrm{g} / \mathrm{mL} \text { against K. oxytoca, } \\
\text { K. pneumoniae and E. coli, respectively }\end{array}$ \\
\hline $\begin{array}{l}\text { Gadisa et al. } \\
{[39]}\end{array}$ & $\begin{array}{l}\text { Blepharis cuspidata, Boswellia } \\
\text { ogadensis, and Thymus schimper }\end{array}$ & & E. coli, K. pneumoniae and MRSA & $\begin{array}{c}\text { MIC: } 0.39-6.25 \mu \mathrm{L} / \mathrm{mL} / \mathrm{MBC} \\
(0.78-12.5 \mu \mathrm{L} / \mathrm{mL}) \text { against } M D R \text { E. coli } \\
\text { and K. pneumoniae }\end{array}$ \\
\hline $\begin{array}{l}\text { Igwaran et al. } \\
{[40]}\end{array}$ & Tagetes minuta & 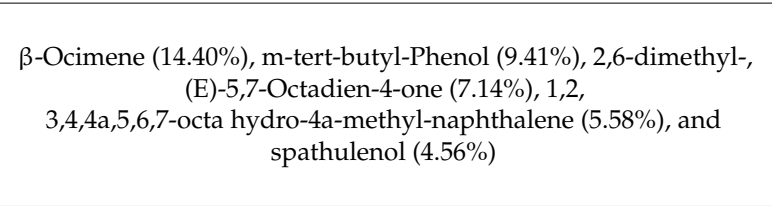 & $\begin{array}{c}\text { S. uberis, E. cloacae, S. aureus, } \\
\text { M. smegmatis, L. ivanovii, Vibrio spp., } \\
\text { E. coli }\end{array}$ & $\begin{array}{l}\text { MIC (S. aureus, M. smegatis, and } \\
\text { S. uberis): } 0.125 \mathrm{mg} / \mathrm{mL} ; \text { L. ivanovii, } \\
\text { Vibrio spp., E. cloacae and E. coli: } \\
0.06 \mathrm{mg} / \mathrm{mL} \text {. MBC (E. cloacae and } \\
\text { E. coli): } 0.06 \mathrm{mg} / \mathrm{mL} ; \text { MBC S. uberis: } \\
0.5 \mathrm{mg} / \mathrm{mL} ; \text { Vibrio spp.: } 0.125 \mathrm{mg} / \mathrm{mL}\end{array}$ \\
\hline $\begin{array}{l}\text { Jaradat et al. } \\
{[41]}\end{array}$ & Thymus bovei & $\begin{array}{c}\text { trans-geraniol }(35.38 \%), \alpha \text {-citral }(20.37 \%), \beta \text {-citral }(14.76 \%) \\
\text { cis-geraniol }(7.38 \%) \text {, and 3-octanol }(4.38 \%)\end{array}$ & $\begin{array}{l}\text { S. aureus, E. coli, P. aeruginosa, } \\
\text { C. albicans }\end{array}$ & MIC: $0.25-0.5 \mathrm{mg} / \mathrm{mL}$ \\
\hline Lee et al. [42] & hibicuslide C & - & P. aeruginosa strains & MIC range: $5.0-10.0 \mu \mathrm{g} / \mathrm{mL}$ \\
\hline $\begin{array}{l}\text { Linde et al. } \\
{[43]}\end{array}$ & Petroselinum crispum & Apiol $(50.3 \%)$, myristicin $(14.0 \%)$, and $\beta$-phellandrene $(14.6 \%)$ & $\begin{array}{l}\text { B. cereus, E. cloacae, L. monocytogenes, } \\
\text { E. coli, P. aeruginosa, S. Typhimurium, } \\
\text { S. aureus }\end{array}$ & $\begin{array}{l}\text { MICs } 0.04-1.0 \mathrm{mg} / \mathrm{mL} . \mathrm{MBCs} \\
0.15-10.0 \mathrm{mg} / \mathrm{mL}\end{array}$ \\
\hline $\begin{array}{l}\text { Mahmoudzadeh } \\
\text { et al. } \\
\text { [44] }\end{array}$ & Carum copticum & $\begin{array}{l}\text { thymol }(36.4 \%), p-C y m e n e(31.4 \%) \\
\text { and } \gamma \text {-Terpinene }(21.73 \%)\end{array}$ & E. coli & $\begin{array}{l}\text { MIC } 0.05 \%-1.75 \% \\
\text { MBC } 0.052 \%-3.25 \%\end{array}$ \\
\hline
\end{tabular}


Table 2. Cont

\begin{tabular}{|c|c|c|c|c|}
\hline Article & Plant Derived EOs & Main Components of EOs & Bacteria & $\mathrm{MIC} / \mathrm{MBC} / \mathrm{IC}_{50}$ \\
\hline $\begin{array}{l}\text { Man et al. } \\
\text { [45] }\end{array}$ & $\begin{array}{l}\text { Boswellia sacra, Myrtus communis, } \\
\text { Thymus vulgaris, Citrus limon, } \\
\text { Origanum vulgare, and Lavandula } \\
\text { angustifolia }\end{array}$ & $\begin{array}{c}\text { Boswellia sacra: } \beta \text {-pinene (25.6\%), } \alpha \text {-terpinene (18.6\%); Myrtus } \\
\text { communis: } \beta \text {-pinene (25\%), eucalyptol (28.7\%); Thymus vulgaris: } \\
\text { linalool (56.5\%), geranyl propionate (16.3\%); Citrus limon: } \\
\text { limonene (36.9\%), } \beta \text {-pinene (15\%), } \alpha \text {-pinene (19.2\%); Origanum } \\
\text { vulgare: carvacrol (80.5\%); Lavandula angustifolia: linalyl-butyrate } \\
(26.5 \%), \text { and linalool }(25 \%)\end{array}$ & $\begin{array}{l}\text { S. aureus, E. faecalis, E. coli, } \\
\text { K. pneumoniae, P. aeruginosa }\end{array}$ & MICs/MBCs $0.1 \%$ to $>50 \%$ \\
\hline $\begin{array}{l}\text { Marrelli et al. } \\
\quad[46]\end{array}$ & $\begin{array}{l}\text { Origanum dictamnus, Origanum } \\
\text { libanoticum and Origanum } \\
\text { microphyllum }\end{array}$ & $\begin{array}{l}\text { O. dictamnus: p-cymene }(32.7 \%), \gamma \text {-terpinene }(12.4 \%) \text {, carvacrol } \\
(14.7 \%) \text {, and linalool }(7.8 \%) ; \text { O. microphyllum: Terpinen-4-ol } \\
(16.2 \%) \text {, carvacrol (13.3\%), sabinene (7.5\%), and } \\
\text { trans-sabinene hydrate }(7.1 \%) ; \text { Origanum libanoticum: linalool } \\
(6.5 \%) \text {, thymol methyl ether }(9.8 \%) \text {, (E)-b-caryophyllene }(7.7 \%) \text {, } \\
\text { and hexadecanoic acid (11.3\%) }\end{array}$ & $\begin{array}{l}\text { B. cereus, B. subtilis, S. epidermidis, } \\
\text { S. aureus, S. faecalis, E. coli }\end{array}$ & O. dictamnus MIC: $25-50 \mathrm{mg} / \mathrm{mL}$ \\
\hline $\begin{array}{l}\text { Meng et al. } \\
\text { [47] }\end{array}$ & Juniperus rigida & Caryophyllene (13.11\%) and $\alpha$-caryophyllene (11.72\%) & K. pneumoniae & MIC/MBC: $3.125 \mathrm{mg} / \mathrm{mL}$ \\
\hline $\begin{array}{l}\text { Montironi et al. } \\
{[48]}\end{array}$ & Minthostachys verticillata & Pulegone $(51.7 \%)$ and menthone $(37.8 \%)$ & S. uberis & $\begin{array}{l}\text { MIC: } 14.3-114.5 \mathrm{mg} / \mathrm{mL} / \mathrm{MBC}: \\
\quad 114.5-229 \mathrm{mg} / \mathrm{mL}\end{array}$ \\
\hline $\begin{array}{l}\text { Mutlu-Ingok } \\
\text { et al. } \\
\quad \text { [49] }\end{array}$ & $\begin{array}{l}\text { Cardamom, cumin, and dill } \\
\text { weed }\end{array}$ & $\begin{array}{c}\text { Cumin: p-mentha-1,3-dien-7-al (26.7\%), cumin aldehyde (24.1\%), } \\
\gamma \text {-terpinene ( } 16.9 \%) \text {, and } \\
\beta \text {-pinene (14.4\%); Cardamom: } \alpha \text {-terpinly acetate (43.4\%) and } \\
\text { 1,8-cineole (29.2\%); Dill weed: carvone (41.6\%), and limonene } \\
(27.4 \%)\end{array}$ & C. jejuni, C. coli & $\begin{array}{c}\text { MIC/MBC: } 0.05 \mathrm{~L} / \mathrm{mL} \text {, cumin, } \\
\text { Cardamonocumin MIC/MBC: } \\
0.025 \mathrm{~L} / \mathrm{mL}\end{array}$ \\
\hline $\begin{array}{l}\text { Okoh et al. } \\
\text { [50] }\end{array}$ & Peperomia pellucida & $\begin{array}{l}\text { Linalool, d-limonene, } \beta \text {-caryophyllene, and linalyl acetate were } \\
\text { the major compounds }\end{array}$ & $\begin{array}{l}\text { S. aureus, L. ivanovii, M. smegmatis, } \\
\text { S. uberis, E. cloacae, E. coli, V. } \\
\text { paraheamolyticus }\end{array}$ & MIC: $0.15-0.20 \mathrm{mg} / \mathrm{mL}$ \\
\hline $\begin{array}{l}\text { Okoh et al. } \\
\text { [51] }\end{array}$ & Jatropha gossypifolia & $\begin{array}{l}\text { Phytol, germacrene } \mathrm{D}, \alpha \text {-copaene, } \alpha \text {-terpinene, and limonene } \\
\text { were the major compounds }\end{array}$ & E. coli, E. faecium, and S. aureus & $\begin{array}{l}\text { MIC/MBC: } 0.025-0.10 \mathrm{mg} / \\
\text { MBC: } 0.05-0.10 \mathrm{mg} / \mathrm{mL}\end{array}$ \\
\hline $\begin{array}{l}\text { Oukerrou et al. } \\
\text { [52] }\end{array}$ & Aloysia citriodora & $\begin{array}{c}\beta \text {-spathulenol (15.61\%), ar-curcumene }(14.15 \%), \\
\text { trans-caryophyllene oxide }(14.14 \%) \text {, and neral }(10.02 \%)\end{array}$ & E. coli, S. aureus, P. aeruginosa & MIC: $2.84-8.37 \mathrm{mg} / \mathrm{mL}$ \\
\hline $\begin{array}{l}\text { Paredes et al. } \\
\text { [53] }\end{array}$ & Senecio nutans & Methyl cinnamate (44.9\%), p-cymenol (27.2\%), & Vibrio cholerae & MIC: $0.4 \mathrm{mg} / \mathrm{mL}$ \\
\hline $\begin{array}{l}\text { Patra et al. } \\
\quad[54]\end{array}$ & Enteromorpha linza & $\begin{array}{l}\text { hexadecanoic acid, nonadecadiene, tetradecanoic acid, tridecanol, } \\
\text { and azetidine }\end{array}$ & B. cereus, S. aureus & MIC/MBC: $12.5-25 \mathrm{mg} / \mathrm{mL}$ \\
\hline Pereira et al. [55] & Baccharis dracunculifolia & - & Streptococcus mutans & MIC: $6 \%$ \\
\hline Porfirio et al. [56] & Lippia alba & $\begin{array}{c}\text { Geranial, neral, p-cymene, geranic acid, carvone, and limonene } \\
\text { were the major compounds }\end{array}$ & S. aureus & $\begin{array}{l}\text { MIC } 0.5-1 \mathrm{mg} / \mathrm{mL} ; \text { MBC: } \\
\quad 0.5-2 \mathrm{mg} / \mathrm{mL}\end{array}$ \\
\hline
\end{tabular}


Table 2. Cont.

\begin{tabular}{|c|c|c|c|c|}
\hline Article & Plant Derived EOs & Main Components of EOs & Bacteria & $\mathrm{MIC} / \mathrm{MBC} / \mathrm{IC}_{50}$ \\
\hline $\begin{array}{l}\text { Puškárová et al. } \\
\text { [57] }\end{array}$ & $\begin{array}{l}\text { O. vulgare, T. vulgaris, S. sclarea, } \\
\text { L. angustifolia, E. Caryophyllata, } \\
\text { and T. plicata }\end{array}$ & - & $\begin{array}{l}\text { E. coli, S. Typhimurium, } \\
\text { Y. enterocolitica, S. aureus, } \\
\text { L. monocytogenes, E. faecalis, B. cereus, } \\
\text { A. protophormiae, P. fragi }\end{array}$ & MIC/MBC: $0.025 \%-0.5 \%$ \\
\hline Sakkas et al. [58] & $\begin{array}{l}\text { Ocimum basilicum } \text { L., } \\
\text { Matricaria chamomilla, L.Thymus } \\
\text { capitatus, L., } \\
\text { Melaleuca alternifolia, Thymus } \\
\text { vulgaris, L. }\end{array}$ & $\begin{array}{c}\text { Ocimum basilicum L.: estragole; Matricaria chamomilla, L.: bisabolol } \\
\text { and trans-b-farnesen; Thymus capitatus, L.: carvacrol and thymol; } \\
\text { Melaleuca alternifolia: terpinen-4-ol and p-cymene; Thymus } \\
\text { vulgaris, L: thymol, p-cymene, and linalool }\end{array}$ & $\begin{array}{l}\text { A. baumannii, E. coli, K. pneumoniae } \\
\text { and P. aeruginosa }\end{array}$ & $\begin{array}{c}\text { MIC/MBC values ranged from } 0.12 \% \\
\text { to } 1.50 \%(v / v) \text { for tea tree oil, } \\
0.25 \%-4 \%(v / v) \text { for origanum and } \\
\text { thyme oil, } 0.50 \% \text { to }>4 \% \text { for basil oil }\end{array}$ \\
\hline Salem et al. [59] & $\begin{array}{l}\text { Cupressus macrocarpa hartw and } \\
\text { Corymbia citriodora (Hook.) }\end{array}$ & $\begin{array}{l}\text { Terpinen-4-ol }(23.7 \%), \alpha \text {-phellandrene }(19.2 \%), \alpha \text {-citronellol } \\
(17.3 \%) \text {, and citronellal were the major constituents of } C \text {. } \\
\text { macrocarpa, and } \alpha \text {-citronellal }(56 \%), \alpha \text {-citronellol }(14.7 \%) \text {, } \\
\text { citronellol acetate }(12.3 \%) \text {, isopulegol, and eucalyptol were the } \\
\text { primary constituents of } C \text {. citriodora }\end{array}$ & $\begin{array}{l}\text { B. cereus, L. monocytogenes, } M . \text { flavus, } \\
\text { S. aureus, D. solani, E. coli, } \\
\text { P. atrosepticum, P. carotovorum subsp. } \\
\quad \text { Carotovorum, P. aeruginosa }\end{array}$ & $\begin{array}{c}\text { MIC C. citriodora leaves } \\
0.06-0.20 \mathrm{mg} / \mathrm{mL}, \mathrm{MBC}: \\
0.12-0.41 \mathrm{mg} / \mathrm{mL} ; \mathrm{MIC} \text { C. macrocarpa: } \\
0.07-0.31 \mathrm{mg} / \mathrm{mL}, \mathrm{MBC}: \\
0.15-0.63 \mathrm{mg} / \mathrm{mL}\end{array}$ \\
\hline $\begin{array}{l}\text { Semeniuc et al. } \\
{[60]}\end{array}$ & Parsley, lovage, basil, and thyme & $\begin{array}{c}\beta \text {-myrcene, } \\
\beta \text {-phellandrene, } \gamma \text {-terpinene, and } \alpha \text {-pinene were the major } \\
\text { compounds }\end{array}$ & $\begin{array}{l}\text { B. cereus, S. aureus, } P \text {. aeruginosa, } \\
\text { E. coli, S. Typhimurium }\end{array}$ & $\begin{array}{c}\text { B. cereus MIC Basil: } 10.8 \mu \mathrm{L} / \mathrm{mL} \text {; } \\
\text { thyme: } 0.56 \mu \mathrm{L} / \mathrm{mL} \text {; S. aureus MIC } \\
\text { Basil: } 2.45 \mu \mathrm{L} / \mathrm{mL} \text { and thyme } \\
0.06 \mu \mathrm{L} / \mathrm{mL} \text {. P. aeruginosa MIC Basil } \\
10.80 \mu \mathrm{L} / \mathrm{mL} \text { and thyme } 0.27 \mu \mathrm{L} / \mathrm{mL} \text {. } \\
\text { S. Typhimurium MIC Basil: } \\
22.68 \mu \mathrm{L} / \mathrm{mL} \text { and thyme: } 0.56 \mu \mathrm{L} / \mathrm{mL}\end{array}$ \\
\hline $\begin{array}{l}\text { Sharafiti } \\
\text { Chaleshtori et al. } \\
\text { [61] }\end{array}$ & $\begin{array}{l}\text { Bunium persicum, } \\
\text { Eucalyptus globulus, and rose } \\
\text { water }\end{array}$ & $\begin{array}{c}\text { B. persicum, } \beta \text {-pinene }(11.72 \%) \text {, p-cymene }(15.47 \%) \text {, g-terpinene } \\
(18.32 \%) \text {, cumin aldehyde }(38.4 \%) \text {, } \\
\text { p-mentha-1,3-dien-7-al (5.37\%), and p-mentha1,4-dien-7-al } \\
(2.86 \%) \text {; } \\
\text { E. globulus, limonene }(9.4 \%) \text { and } 1,8 \text {-cineole }(70.3 \%) \text {; rose water, } \\
\text { linalool (6.6\%), terpineol }(3.3 \%) \text {, carvone }(0.31 \%) \text {, citronellol } \\
(6.85 \%) \text {, trans-geraniol }(7.11 \%), \text { phenylethanol }(66.84 \%) \text {, eugenol } \\
(4.53 \%) \text {, cytronellol, hydroxyl }(1.15 \%) \text {, and geranic acid }(1.2 \%)\end{array}$ & Listeria spp. & $\begin{array}{l}\text { MIC: } 0.351-2.812 \mathrm{mg} / \mathrm{mL} \\
\text { MBC: } 0.703-5.625 \mathrm{mg} / \mathrm{mL}\end{array}$ \\
\hline Sharifi et al. [62] & $\begin{array}{l}\text { Thymus daenensis; } \\
\text { Satureja hortensis }\end{array}$ & $\begin{array}{c}\text { T. daenensis: carvacol }(40 \%-69 \%) \text {, } \\
\text { followed by } \gamma \text {-terpinene }(30 \%-28 \%) \text { and } \alpha \text {-terpinene }(5 \%-52 \%) \text {; } \\
\text { S. hortensis: thymol }(41 \%-28 \%), \gamma \text {-terpinene }(37 \%-63 \%) \text {, } \\
\text { p-cymene }(2 \%-12 \%) \text { and } \alpha \text {-terpinene }(3 \%-52 \%)\end{array}$ & S. aureus & $\begin{array}{l}\text { MICs of T. daenensis: } 0.0625 \mu \mathrm{L} / \mathrm{mL} ; \\
\text { S. hortensis } 0.125 \mu \mathrm{L} / \mathrm{mL} ; \mathrm{MBC} \\
\quad 0.125 \mu \mathrm{L} / \mathrm{mL}\end{array}$ \\
\hline $\begin{array}{l}\text { Sharifi-Rad et al. } \\
{[63]}\end{array}$ & Xanthium strumarium L. & $\begin{array}{c}\text { cis- } \beta \text {-guaiene (34.2\%), limonene ( } 20.3 \%) \text {, borneol (11.6\%), and } \\
\text { bornyl acetate }(4.5 \%)\end{array}$ & $\begin{array}{l}\text { K. pneumoniae, E. coli, P. aeruginosa, } \\
\text { S. aureus, S. epidermis, B. subtilis }\end{array}$ & $\begin{array}{l}\text { MIC S. aureus: } 0.5 \mu \mathrm{g} / \mathrm{mL} ; \mathrm{MIC} \\
\text { B. subtilis } 1.3 \mu \mathrm{g} / \mathrm{mL} ; \mathrm{MIC} \\
\text { K. pneumoniae } 4.8 \mu \mathrm{g} / \mathrm{mL}\end{array}$ \\
\hline
\end{tabular}


Table 2. Cont.

\begin{tabular}{|c|c|c|c|c|}
\hline Article & Plant Derived EOs & Main Components of EOs & Bacteria & $\mathrm{MIC} / \mathrm{MBC} / \mathrm{IC}_{50}$ \\
\hline Smeriglio et al. & Pistacia vera $\mathrm{L}$. & $\begin{array}{l}\text { 4-Carene, } \alpha \text {-pinene, and } \\
\delta \text {-3-Carene were the major compounds }\end{array}$ & $\begin{array}{c}\text { S. aureus, S. aureus MRSA, three } \\
\text { clinical isolates of S. aureus, E. coli and } \\
\text { P. aeruginosa }\end{array}$ & $\begin{array}{l}\text { MIC/MBC: } 7.11 \mathrm{mg} / \mathrm{mL} \text { inhibited the } \\
\text { growth of all the tested strains, with } \\
\text { the exception of Pseudomonas }\end{array}$ \\
\hline Snoussi et al. [65] & $\begin{array}{l}\text { Petroselinum crispum, Ocimum } \\
\text { basilicum }\end{array}$ & $\begin{array}{c}\text { P. crispum: } 1,3,8-p-\text {-menthatriene }(24.2 \%), \beta \text {-phellandrene }(22.8 \%) \text {, } \\
\text { apiol }(13.2 \%) \text {, myristicin }(12.6 \%) \text {, and terpinolene }(10.3 \%) ; \\
\text { O. basilicum: linalool }(42.1 \%),(\mathrm{E}) \text {-methylcinnamate }(16.9 \%) \text {, and } \\
1,8 \text {-cineole }(7.6 \%)\end{array}$ & $\begin{array}{c}\text { V. alginolyticus, V. alginolyticus, } \\
\text { V. parahaemolyticus, } \\
\text { V. parahaemolyticus, Vibrio vulnificus, } \\
\text { V. vulnificus, V. cholerae, A. hydrophila }\end{array}$ & $\begin{array}{l}\text { P. crispum: MIC: } 0.011-0.044 \mathrm{mg} / \mathrm{mL} \\
\text { MBC:2.81-11.25 mg/mL; O. basilicum } \\
\text { MIC 0.019-0.039 mg/mL; MBC } \\
2.5-10 \mathrm{mg} / \mathrm{mL}\end{array}$ \\
\hline $\begin{array}{l}\text { Soliman et al. } \\
{[66]}\end{array}$ & Calligonum comosum & Benzaldehyde derivative was the major compound & $\begin{array}{l}\text { P. aeruginosa, K. pneumoniae, } \\
\text { A. baumannii, and E. coli }\end{array}$ & MIC: $180.0-200.0 \mu \mathrm{g} / \mathrm{mL}$ \\
\hline $\begin{array}{l}\text { Tibyangye et al. } \\
{[67]}\end{array}$ & Ocimum suave & Linalool and geraniol were the major compounds & $\begin{array}{l}\text { E. coli, K. pneumoniae, S. aureus, } \\
\text { E. faecalis, M. morganii, Citrobacter spp., } \\
\text { Enterobacter spp. and P. aeruginosa }\end{array}$ & MIC: $0.78-22 \mu \mathrm{g} / \mathrm{mL}$ \\
\hline Touihri et al. [68] & Allium roseum & $\begin{array}{l}\text { Methyl methanethiosulfinate, 3-vinyl-1,2-dithiacyclohex-5-ene, } \\
\text { and diallyl trisulfide were the major compounds }\end{array}$ & $\begin{array}{l}\text { S. aureus, K. pneumoniae, E. coli, } \\
\text { E. faecalis, S. Typhimurium }\end{array}$ & MIC: $0.078-2.5 \mathrm{mg} / \mathrm{mL}$ \\
\hline Ušjak et al. [69] & $\begin{array}{l}\text { Heracleum pyrenaicum subsp. } \\
\text { orsinii (Guss.) }\end{array}$ & $\begin{array}{l}\beta \text {-pinene, }(Z)-\beta \text {-ocimene, and } \alpha \text {-pinene were the major } \\
\text { compounds }\end{array}$ & $\begin{array}{l}\text { S. aureus, B. cereus, L. monocytogenes, } \\
\text { M. flavus, } P \text {. aeruginosa, E. coli, } \\
\text { S. Typhimurium, E. cloacae }\end{array}$ & $\begin{array}{l}\text { B. cereus (MIC: } 0.21 \mathrm{mg} / \mathrm{mL}, \mathrm{MBC}: \\
0.53 \mathrm{mg} / \mathrm{mL}) \text {. S. Typhimurium, E. coli, } \\
\text { P. aeruginosa (MICs: } 0.23 \mathrm{mg} / \mathrm{mL} \text {, } \\
\text { MBCs: } 0.47 \mathrm{mg} / \mathrm{mL}) \text {, S. aureus (MIC: } \\
0.23 \mathrm{mg} / \mathrm{mL}, \mathrm{MBC}: 0.47 \mathrm{mg} / \mathrm{mL} \text { ) }\end{array}$ \\
\hline $\begin{array}{l}\text { Utegenova et al. } \\
{[70]}\end{array}$ & Ferula ovina (Boiss.) & $\begin{array}{c}\alpha \text {-pinene }(47.8 \%), \beta \text {-pinene }(7.1 \%) \text {, sabinene }(20.5 \%), \\
\beta \text {-phellandrene }(6.5 \%) \text {, and trans-verbenol }(7.4 \%)\end{array}$ & MRSA & $\mathrm{IC}_{50}: 19.1-22.9 \mu \mathrm{g} / \mathrm{mL}$ \\
\hline Vieira et al. [71] & $\begin{array}{l}\text { Eucalyptus globulus, Thymus } \\
\text { mastichina L., Mentha pulegium } \\
\text { L., Rosmarinus officinalis L., } \\
\text { Calamintha nepeta, Cistus } \\
\text { ladanifer L., Foeniculum vulgare } \\
\text { L., Dittrichia viscosa }\end{array}$ & $\begin{array}{l}\text { Lamiaceae: isopulegol, isopulegone and 1,8-Cineole; C. nepeta: } \\
\text { pulegone; M. pulegium: } \beta \text {-myrcene, camphor, } 1,8 \text {-cineole; } R \text {. } \\
\text { officinalis: } \alpha \text {-pinene, and 1,8-cineole; T. mastichina: } \alpha \text {-terpinyl } \\
\text { acetate; C. ladanifer: } \alpha \text {-pinene, camphene, fenchone, bornyl } \\
\text { acetate, and viridiflorol; E. globulus: } \\
\text { 1,8-cineole; F. vulgare: anethol, b-myrcene and fenchone; } \\
\text { D. viscosa: E-nerolidol and fokienol }\end{array}$ & $\begin{array}{l}\text { S. aureus, B. subtilis, E. coli, } \\
\text { P. aeruginosa }\end{array}$ & MIC: $6-25 \mathrm{mg} / \mathrm{mL}$ \\
\hline Xu et al. [72] & Syringa yunnanensis & $\begin{array}{c}\text { Eugenol }(76.23 \%), \beta \text {-caryophyllene }(11.54 \%) \text {, caryophyllene oxide } \\
(4.29 \%) \text {, and eugenyl acetate }(1.76 \%)\end{array}$ & S. aureus & MIC: $0.625 \mathrm{mg} / \mathrm{mL}$ \\
\hline Zhao et al. [73] & $\begin{array}{c}\text { Fagopyrum esculentum, } \\
\text { Fagopyrum tataricum, Fagopyrum } \\
\text { Cymosum }\end{array}$ & 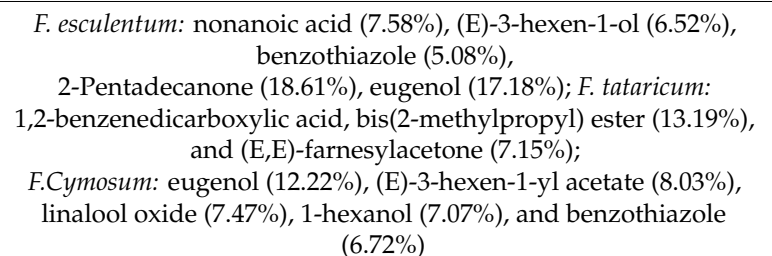 & $\begin{array}{l}\text { A. tumefaciens, E. coli, P. lachrymans, } \\
\text { X. vesicatoria, B. subtilis, S. aureus }\end{array}$ & MIC: $100.0-800.0 \mathrm{~g} / \mathrm{mL}$ \\
\hline
\end{tabular}

Abbreviations: EO, essential oil; MIC, minimal inhibitory concentration; $\mathrm{MBC}$, minimal bactericidal concentration; $\mathrm{IC}_{50}$ half-maximal inhibitory concentration; $\mathrm{MRSA}$, methicillin-resistant S. aureus. 
Table 3. Main characteristics of studies related with antioxidant properties of essential oils.

\begin{tabular}{|c|c|c|c|c|}
\hline Article & Plant Derived EOs & Main Components of EOs & Method & Antioxidant Effects \\
\hline Bag et al. [74] & $\begin{array}{l}\text { Bay leaf, black pepper, coriander, } \\
\text { cumin, garlic, ginger, mustard, onion, } \\
\text { and turmeric }\end{array}$ & $\begin{array}{l}\text { Coriander and cumin seed oil, linalool, p-coumaric } \\
\text { acid }\end{array}$ & DPPH method & $\begin{array}{l}\text { Coriander } 150.62(\mu \mathrm{g} / \mathrm{mL}), \text { cumin } 163.50 \\
(\mu \mathrm{g} / \mathrm{mL}), \text { mustard } 155.16(\mu \mathrm{g} / \mathrm{mL})\end{array}$ \\
\hline Djenane et al. [75] & $\begin{array}{l}\text { Orange (Citrus sinensis L.), lemon } \\
\text { (Citrus limonum } \mathrm{L} .) \text {, and bergamot } \\
\text { (Citrus aurantium L.) from Algeria }\end{array}$ & $\begin{array}{c}\text { Limonene }(77.37 \%) \text { for orange EO; linalyl acetate } \\
(37.28 \%) \text {, linalool ( } 23.36 \%) \text { for bergamot EO; and } \\
\text { limonene } \\
(51.39 \%), \beta \text {-pinene (17.04\%), and } \gamma \text {-terpinene }(13.46 \%) \\
\text { for lemon EO }\end{array}$ & $\begin{array}{l}\text { Antioxidant effect in treated } \\
\text { sardine }\end{array}$ & $\begin{array}{l}\text { A reduction of } 2.50 \log 10 \mathrm{CFU} / \mathrm{g} \text { was recorded } \\
\text { during the third day of storage }\end{array}$ \\
\hline Ehsani et al. [76] & $\begin{array}{l}\text { Melissa officinalis and Deracocephalum } \\
\text { moldavica }\end{array}$ & $\begin{array}{l}\text { M. officinalis, citronellal, thymol, and citral; } D \text {. } \\
\text { moldavica, geraniol, geranial, geranyl acetate, and neral }\end{array}$ & DPPH, BCBT, and ABTS assay & $\begin{array}{l}\text { Both EOs showed strong activity in the } \\
\text { maintenance of } \beta \text {-carotene molecules, which } \\
\text { was higher than that of ascorbic acid }\end{array}$ \\
\hline Hu et al. [77] & Cyperus rotundus $\mathrm{L}$. & $\begin{array}{l}\alpha \text {-pinene, cyperene, } \alpha \text {-cyperone, and cyperotundone } \\
\text { were the major compounds }\end{array}$ & DPPH and ABTS radicals & $\begin{array}{c}\text { DPPH radicals were far lower than that of } \\
\text { Trolox (13.1 } \mu \mathrm{g} / \mathrm{mL}) \text {; however, ABTS radicals } \\
\text { were significantly higher than Trolox } \\
(84.7 \mu \mathrm{g} / \mathrm{mL})\end{array}$ \\
\hline Jaradat et al. [78] & Ruta chalepensis & $\begin{array}{l}\text { Linalyl acetate, } \beta \text {-linalool, 2-undecanone, and } \\
\text { 2-nonanone were the major compounds }\end{array}$ & DPPH method & $\begin{array}{c}\text { Percentages of inhibition for } R \text {. chalepensis } \\
\text { collected from Jerusalem, hebron, and Jenin } \\
\text { were } 6.9 \pm 0.94 \mu \mathrm{g} / \mathrm{mL}, 69.56 \% ; 7.8 \pm \\
1.05 \mu \mathrm{g} / \mathrm{mL}, 61.53 \% \text {; and } 19.9 \pm 0.68 \mu \mathrm{g} / \mathrm{mL} \\
24.12 \% \text {, respectively }\end{array}$ \\
\hline Kazemi et al. [79] & $\begin{array}{l}\text { Achillea millefolium L., Anethum } \\
\text { graveolens L., and Carum copticum L. }\end{array}$ & $\begin{array}{l}\text { A. millefolium, thymol, carvacrol, borneol, and } \\
\text { limonene; A. graveolens, thymol, limonene, } \alpha \text {-pinene; } \\
\text { and C. copticum, thymol, sabinene, and borneol }\end{array}$ & DPPH, FRAP, and BCBT assays & $\begin{array}{l}\text { A. millefolium had the highest antioxidant } \\
\text { activity in all conducted assays }\end{array}$ \\
\hline Marin et al. [80] & $\begin{array}{l}\text { Foeniculum vulgare, Petroselium } \\
\text { crispum, and Lavandula officinalis }\end{array}$ & $\begin{array}{l}\text { L. officinalis, linalool, and linalyl acetate; } F \text {. Vulgare, } \\
\text { limonene, anethole, and fenchone; P. crispum, } \\
\text { myristicin, } \alpha \text {-pinene, and } \beta \text {-pinene }\end{array}$ & DPPH and FRAP assays & $\begin{array}{l}\text { P. crispum presented the best antioxidant } \\
\text { profile, given its highest } \% \text { of inhibition of } \\
\text { DPPH radical ( } 64.28 \%) \text { and FRAP } \\
(0.93 \mathrm{mmol} / \mathrm{L} \text { Trolox })\end{array}$ \\
\hline Marrelli et al. [81] & $\begin{array}{l}\text { Six different populations of } \\
\text { Origanum heracleoticum L. }\end{array}$ & $\begin{array}{l}\text { Limonene, carvacrol-methyl-ether, and carvacrol were } \\
\text { the major compounds }\end{array}$ & DPPH and BCBT assays & $\begin{array}{l}\text { Samples showed a modest DPPH value of } \\
320.9 \mu \mathrm{g} / \mathrm{mL} \text {, and BCBT of } 4.68 \mu \mathrm{g} / \mathrm{mL} \text {. }\end{array}$ \\
\hline Okoh et al. [82] & Dennettia tripetala G. Baker & $\begin{array}{l}\text { 2-Methylphenyl formate, } \alpha \text {-terpinene, and } \\
\text { caryophyllene were the major compounds }\end{array}$ & $\begin{array}{l}\text { DPPH, ABTS, nitric oxide, and } \\
\text { lipid peroxyl }\end{array}$ & $\begin{array}{l}\text { The EOs demonstrated strong ability in ABTS, } \\
\text { lipid peroxide, and nitric oxide radical assays } \\
\text { in a concentration-dependent manner }\end{array}$ \\
\hline Okoh et al. [51] & Jatropha gossypifolia L. & $\begin{array}{l}\text { Phytol, germacrene } \mathrm{D}, \alpha \text {-copaene, } \alpha \text {-terpinene, and } \\
\text { limonene were the major compounds }\end{array}$ & $\begin{array}{l}\text { DPPH, ABTS, nitric oxide, and } \\
\text { lipid peroxyl }\end{array}$ & $\begin{array}{l}\text { The stem showed that the antiradical strength } \\
\text { was superior to leaf EO }\end{array}$ \\
\hline
\end{tabular}


Table 3. Cont

\begin{tabular}{|c|c|c|c|c|}
\hline Article & Plant Derived EOs & Main Components of EOs & Method & Antioxidant Effects \\
\hline Okoh et al. [50] & Peperomia pellucida (L.) Kunth & $\begin{array}{l}\text { Linalool, } \mathrm{d} \text {-limonene, } \beta \text {-caryophyllene, and linalyl } \\
\text { acetate were the major compounds }\end{array}$ & $\begin{array}{l}\text { DPPH, ABTS, nitric oxide, and } \\
\text { lipid peroxyl }\end{array}$ & $\begin{array}{l}\text { The EOs demonstrated strong ability in DPPH } \\
\text { ABTS, nitric oxide and lipid peroxyl assays in a } \\
\text { concentration-dependent manner }\end{array}$ \\
\hline Ouedrhiri et al. [83] & $\begin{array}{l}\text { Ormenis mixta and Pelargonium } \\
\text { asperum }\end{array}$ & $\begin{array}{c}\text { P. asperum, citronellol, } \\
\text { citronellyl formate, and geraniol; O. mixta, germacrene, } \\
1,8 \text { cineol, and } \\
\text { cis-methyl isoeugenol }\end{array}$ & DPPH method & $\begin{array}{l}\text { O. mixta exhibited an important antioxidant } \\
\text { activity, which was significantly higher than } \\
\text { that exhibited by } P \text {. asperum }\end{array}$ \\
\hline Pirbalouti et al. [84] & Ferulago angulata & $\begin{array}{c}\alpha \text {-pinene, and cis- } \beta \text {-ocimene were the major } \\
\text { compounds }\end{array}$ & DPPH method & $\begin{array}{l}\text { The highest antioxidant activity was obtained } \\
\text { from the oil of the Kallar population } \\
(488 \mu \mathrm{g} / \mathrm{mL}) \text { and butylhydroxyanisole as a } \\
\text { positive control }(321 \mu \mathrm{g} / \mathrm{mL})\end{array}$ \\
\hline Poaty et al. [85] & $\begin{array}{l}\text { Balsam fir, black spruce, white spruce, } \\
\text { tamarack, jack pine, eastern white } \\
\text { cedar, and Labrador tea EOs }\end{array}$ & $\begin{array}{c}\alpha \text {-pinene, } \beta \text {-pinene, } \delta \text {-3-carene, and limonene were } \\
\text { the major compounds. } \alpha \text {-thujone was the main } \\
\text { compound in white cedar }\end{array}$ & DPPH, FRAP assays & $\begin{array}{c}\text { DPPH (concentration providing 50\% inhibition } \\
\qquad 7 \mathrm{mg} / \mathrm{mL} \text { ) }\end{array}$ \\
\hline Semeniuc et al. [86] & Parsley, lovage, basil, and thyme EOs & $\begin{array}{c}\beta \text {-myrcene, } \\
\beta \text {-phellandrene, } \gamma \text {-terpinene, and } \alpha \text {-pinene were the } \\
\text { major compounds }\end{array}$ & TEAC assay & $\begin{array}{c}\text { The highest antioxidant capacity was found in } \\
\text { thyme oil }\end{array}$ \\
\hline Shakeri et al. [87] & $\begin{array}{l}\text { Glycyrrhiza triphylla Fisch. and } \\
\text { C.A.Mey }\end{array}$ & $\begin{array}{l}\beta \text {-caryophyllene, limonene, and myrcene were the } \\
\text { major compounds }\end{array}$ & $\begin{array}{c}\text { The DPPH, and } \\
\beta \text {-Carotene/linoleic acid assay }\end{array}$ & $\begin{array}{l}\text { The oil was considerably active in the DPPH } \\
\text { assay }(100.40 \pm 0.03 \mu \mathrm{g} / \mathrm{mL})\end{array}$ \\
\hline $\begin{array}{l}\text { Sharafati Chaleshtori } \\
\text { et al. [61] }\end{array}$ & $\begin{array}{c}\text { Bunium persicum, } \\
\text { Eucalyptus globulus, and rose water }\end{array}$ & 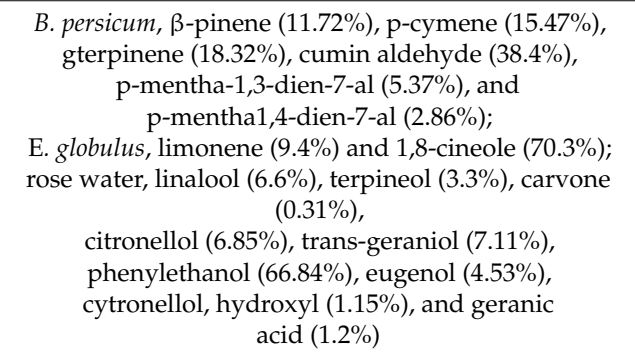 & FRAP & $\begin{array}{l}\text { Bunium persicum EO showed the greatest } \\
\text { antioxidant activity }\end{array}$ \\
\hline Smeriglio et al. [64] & Pistacia vera $\mathrm{L}$. & $\begin{array}{l}\text { 4-carene, } \alpha \text {-pinene, and } \\
\delta \text {-3-carene were the major compounds }\end{array}$ & $\begin{array}{l}\text { Determination of total phenolic } \\
\text { compounds, DPPH, TEAC, } \\
\text { FRAP, chelating capacity on } \\
\mathrm{Fe}^{2+}, \mathrm{BCBT} \text { assays, superoxide } \\
\text { anion }\left(\mathrm{O}^{2-}\right) \text { scavenging assay } \\
\text { and hydroxyl radical }(-\mathrm{OH}) \\
\text { scavenging assay }\end{array}$ & $\begin{array}{c}\text { The Pistacia vera L. variety Bronte showed a } \\
\text { strong iron-chelating activity and was found to } \\
\text { be markedly active against hydroxyl radical, } \\
\text { while little effect was found against the DPPH } \\
\text { method }\end{array}$ \\
\hline
\end{tabular}


Table 3. Cont

\begin{tabular}{|c|c|c|c|c|}
\hline Article & Plant Derived EOs & Main Components of EOs & Method & Antioxidant Effects \\
\hline Snoussi et al. [88] & Mentha spicata & $\begin{array}{l}\text { Limonene, 1,8-cineole, and carvone were the major } \\
\text { compounds }\end{array}$ & $\begin{array}{l}\text { DPPH method, reducing power, } \\
\text { chelating power, and BCBT } \\
\text { assays }\end{array}$ & $\begin{array}{c}\text { DPPH IC } 503.08 \pm 0.07 \text {, reducing power } \mathrm{EC}_{50} \\
2.49 \pm 0.07 \text {, chelating power } \mathrm{IC}_{50}, 6.33 \pm 0.12 \\
\text { and BCBT } 6.4 \pm 0.07\end{array}$ \\
\hline $\begin{array}{l}\text { Salem et al. } \\
\text { [59] }\end{array}$ & $\begin{array}{l}\text { Cupressus macrocarpa and } \\
\text { Corymbia citriodora }\end{array}$ & $\begin{array}{c}\text { Terpinen-4-ol (23.7\%), } \alpha \text {-phellandrene }(19.2 \%), \\
\alpha \text {-citronellol (17.3\%), and citronellal were the major } \\
\text { constituents of C. macrocarpa, and } \alpha \text {-citronellal }(56 \%), \\
\alpha \text {-citronellol (14.7\%), citronellol acetate }(12.3 \%), \\
\text { isopulegol, and eucalyptol were the primary } \\
\text { constituents of C. citriodora }\end{array}$ & Standard butylhydroxytoluene & $\begin{array}{l}\text { C. citriodora was higher than that of the } \\
\text { positive control but lower than that of the } \\
\text { standard, butylhydroxytoluene }\end{array}$ \\
\hline $\begin{array}{l}\text { Zhao et al. } \\
\text { [73] }\end{array}$ & $\begin{array}{c}\text { Fagopyrum esculentum, Fagopyrum } \\
\text { tataricum, and } \\
\text { Fagopyrum Cymosum }\end{array}$ & $\begin{array}{l}\text { F. esculentum: Nonanoic acid (7.58\%), (E)-3-hexen-1-ol } \\
(6.52 \%), \text { benzothiazole }(5.08 \%), 2 \text {-Pentadecanone } \\
(18.61 \%) \text {, and eugenol (17.18\%); } \\
\text { F. tataricum: 1,2-benzenedicarboxylic acid, } \\
\text { bis(2-methylpropyl) ester (13.19\%) and } \\
\text { (E,E)-farnesylacetone (7.15\%); } \\
\text { F.Cymosum: Eugenol (12.22\%), (E)-3-hexen-1-yl acetate } \\
(8.03 \%) \text {, linalool oxide (7.47\%), 1-hexanol (7.07\%), and } \\
\text { benzothiazole (6.72\%) }\end{array}$ & DPPH and BCBT assays & $\begin{array}{l}\text { Three EOs have a similar antioxidant capacity } \\
\text { in both evaluated methods }\end{array}$ \\
\hline
\end{tabular}

Abbreviations: EOs: essential oils; ABTS, 2,2'-azino-bis(3-ethylbenzothiazoline-6-sulphonic acid); BCBT, $\beta$-carotene bleaching test; CFU, colony-forming unit; DPPH, (2,2-diphenyl-1-picrylhydrazyl); FRAP, ferric-reducing antioxidant power; TEAC, Trolox equivalent antioxidant capacity. 
Table 4. Main characteristics of studies related with immunomodulatory properties of essential oils in cells.

\begin{tabular}{|c|c|c|c|c|c|c|c|}
\hline Author & Cell Line & Plant Derived EOs & EOs Concentration & $\begin{array}{l}\text { Main } \\
\text { Components of } \\
\text { EOs }\end{array}$ & Exposure Time & LPS Stimulation & Main Results \\
\hline $\begin{array}{l}\text { Chen et al. } \\
\text { [31] }\end{array}$ & $\begin{array}{c}\text { THP-1 human } \\
\text { monocyte/macrophage } \\
\text { cell line }\end{array}$ & Kanuka and manuka & $0.1-0.5-1-5-10 \%$ & & $48 \mathrm{~h}$ & yes $(20 \mu \mathrm{g} / \mathrm{mL})$ & $\begin{array}{l}\text { EOs have no major toxic side effects on } \\
\text { THP-1 cells. Kanuka and manuka EOs } \\
\text { reduced the LPS-induced TNF- } \alpha \text { secretion } \\
\text { but have no effect on IL-4 secretion. Kanuka } \\
\text { and manuka EO have no effect on } \\
\text { unstimulated THP-1 cells. }\end{array}$ \\
\hline Chen et al. [89] & $\begin{array}{l}\text { C57BL/6 mouse bone } \\
\text { marrow-derived } \\
\text { dendritic cells (DCs) }\end{array}$ & Litsea cubea $\mathrm{L}$. & $\begin{array}{c}1-2-4 \times 10^{5} \text { - and } \\
5 \times 10^{4} \text {-fold dilution }\end{array}$ & $\begin{array}{l}\text { Terpene aldehydes } \\
(75.09 \%) \text { were the } \\
\text { most abundant } \\
\text { compounds }\end{array}$ & $\begin{array}{l}\text { Cytotoxicity assay: } \\
24 \text { h; TNF- } \alpha \text { assay: } \\
6 \text { h; IL-12 assay: } 12 \text { h }\end{array}$ & yes $(100 \mathrm{ng} / \mathrm{mL})$ & $\begin{array}{l}\text { A slight cytotoxic effect was observed at } \\
5 \times 10^{4} \text {-fold diluted EO. Release of TNF- } \alpha \\
\text { and IL- } 12 \text { by LPS-induced DCs were } \\
\text { inhibited by EO in a dose-dependent fashion } \\
\text { (IC } 50 \text { of } 1 \times 10^{5} \text { - and } 2 \times 10^{5} \text {-fold dilution for } \\
\text { TNF- } \alpha \text { and IL- } 12 \text {, respectively). }\end{array}$ \\
\hline Chen et al. [22] & $\begin{array}{l}\text { Murine macrophage } \\
\text { RAW264.7 cells }\end{array}$ & Artemisia argyi & $\begin{array}{c}270,90,30, \text { and } \\
10 \mu \mathrm{g} / \mathrm{mL})\end{array}$ & $\begin{array}{l}\text { Cineole, camphor, } \\
(-) \text {-borneol, and } \\
\alpha-(-) \text {-thujone } \\
\text { were the major } \\
\text { compounds }\end{array}$ & $16 \mathrm{~h}$ & yes $(1 \mu \mathrm{g} / \mathrm{mL})$ & $\begin{array}{l}\text { In LPS-induced cells, the EOs inhibited the } \\
\text { release of NO, PGE } 2 \text {, and ROS and TNF- } \alpha \text {, } \\
\text { IL-6, IFN- } \beta \text { and MCP- } 1 \text {. In addition, EOs } \\
\text { downregulate the gene and protein } \\
\text { expression of iNOS and COX- } 2 \text { without } \\
\text { affecting its enzymatic activity. EOs also } \\
\text { inhibited the phosphorylation of JAK2 and } \\
\text { STAT1/ } 3 \text { but did not affect the MAPK and } \\
\text { NF-kB cascades. }\end{array}$ \\
\hline Cheng et al. [90] & $\begin{array}{l}\text { Murine macrophage } \\
\text { RAW264.7 cell }\end{array}$ & $\begin{array}{l}\text { Oregano (Origanum } \\
\text { vulgare L.) }\end{array}$ & $\leq 10 \mu \mathrm{g} / \mathrm{mL}$ & $\begin{array}{l}\text { Carvacrol and } \\
\text { thymol were the } \\
\text { major compounds }\end{array}$ & $12 \mathrm{~h}$ & yes $(1 \mu \mathrm{g} / \mathrm{mL})$ & $\begin{array}{l}\text { Low dose of EOs }(1.25-20 \mu \mathrm{g} / \mathrm{mL}) \text { did not } \\
\text { produce any toxicity. In LPS-induced } \\
\text { RAW264.7 cells, pretreatment with the EOs } \\
\text { reduced the expression and secretion of } \\
\text { IL-1 } \beta \text {, IL-6, and TNF- } \alpha \text {. Inhibition of } \\
\text { LPS-induced MAPK, PKB, and NF-kB was } \\
\text { also observed. The EOs also inhibited the } \\
\text { LPS-induced elevation of NADPH oxidase } \\
\text { and oxidative stress }\end{array}$ \\
\hline Krifa et al. [91] & $\begin{array}{l}\text { Splenocyte suspension } \\
\text { from Balb/c mice; } \\
\text { Murine melanoma } \\
\text { B16F10 cell line }\end{array}$ & Pituranthos tortuosus & $\begin{array}{c}\text { Splenocyte suspension: } \\
1.25,2.5,5 \text {, and } \\
10 \mu \mathrm{g} / \mathrm{mL} . \mathrm{B} 16 \mathrm{~F} 10 \text { cell } \\
\text { line: } 25,50,100,200, \\
\text { and } 400 \mu \mathrm{g} / \mathrm{mL} \text {. }\end{array}$ & $\begin{array}{l}\text { Sabinene, } \\
\alpha \text {-pinene, } \\
\text { limonene, and } \\
\text { terpinen-4-ol were } \\
\text { the major } \\
\text { compounds }\end{array}$ & $48 \mathrm{~h}$ & yes $(5 \mu \mathrm{g} / \mathrm{mL})$ & $\begin{array}{l}\text { EOs treatment was able to promote } \\
\text { LPS-stimulated splenocyte proliferation. In } \\
\text { B16F10 cells, incubation with the EOs } \\
\text { inhibited cell proliferation in a dose- and } \\
\text { time-dependent fashion (IC50: } 80 \mu \mathrm{\mu g} / \mathrm{mL} \text { ). In } \\
\text { addition, EOs treatment was also able to } \\
\text { increase the number of apoptotic cells. }\end{array}$ \\
\hline
\end{tabular}


Table 4. Cont.

\begin{tabular}{|c|c|c|c|c|c|c|c|}
\hline Author & Cell Line & Plant Derived EOs & EOs Concentration & $\begin{array}{c}\text { Main } \\
\text { Components of } \\
\text { EOs }\end{array}$ & Exposure Time & LPS Stimulation & Main Results \\
\hline Ma et al. [92] & $\begin{array}{l}\text { L02 cell line; human } \\
\text { lung adenocarcinoma } \\
\text { A549 cell line; Murine } \\
\text { macrophage RAW264.7 } \\
\text { cell }\end{array}$ & $\begin{array}{c}\text { Cirsium japonicum } \\
\text { DC }\end{array}$ & $\begin{array}{c}25,50,100, \text { and } \\
200 \mu \mathrm{g} / \mathrm{mL}\end{array}$ & $\begin{array}{l}\text { Flavonoids, } \\
\text { saponins, } \\
\text { polysaccharides } \\
\text { EO, coumarin, and } \\
\text { alkaloids }\end{array}$ & $24 \mathrm{~h}$ & yes $(1 \mu \mathrm{g} / \mathrm{mL})$ & $\begin{array}{l}\text { EOs have no major toxic side effects on L02 } \\
\text { cells, and even promoted cell proliferation. } \\
\text { In the A549 cell line, EOs promote the } \\
\text { proliferation of cancer cells. NO production } \\
\text { was inhibited in LPS-induced RAW264.7 } \\
\text { cells treated with EOs at } 50 \text { and } 100 \mathrm{\mu g} / \mathrm{mL} \\
\text { In addition, EOs treatment reduces the } \\
\text { secretion of IL-6, but has no effect on TNF- } 0 \\
\text { gene expression. Furthermore, EOs } \\
\text { decreased lipid accumulation in } \\
\text { ox-LDL-induced RAW264.7 cell, and } \\
\text { decreased the secretion of IL-6. }\end{array}$ \\
\hline Marelli et al. [81] & $\begin{array}{l}\text { Murine macrophage } \\
\text { RAW264.7 cells }\end{array}$ & $\begin{array}{c}\text { Origanum heracleticum } \\
\text { L. }\end{array}$ & $25-1000 \mu \mathrm{g} / \mathrm{mL}$ & $\begin{array}{l}\text { Limonene, } \\
\text { carvacrol-methyl-ether, } \\
\text { and carvacrol were } \\
\text { the major } \\
\text { compounds }\end{array}$ & $24 \mathrm{~h}$ & yes $(1 \mu \mathrm{g} / \mathrm{mL})$ & $\begin{array}{l}\text { In LPS-stimulated RAW264.7 cells, all EOs } \\
\text { from Origanun heracleticum } \mathrm{L} \text {. showed } \\
\text { anti-inflammatory activity by means of its } \\
\text { capacity to decrease the NO production. }\end{array}$ \\
\hline Özek et al. [93] & $\begin{array}{l}\text { human blood isolated } \\
\text { neutrophils } \\
\text { from healthy donors; } \\
\text { bone marrow leukocytes } \\
\text { isolated from Balb/c } \\
\text { mice }\end{array}$ & Ferula iliensis & $1 \%$ & $\begin{array}{l}\text { (E)-Propenyl sec } \\
\text { butyl disulfide, } \\
\text { (Z)-Propenyl sec } \\
\text { butyl disulfide, } \\
\text { and } \\
\text { 10-Epi-g-eudesmol } \\
\text { were the major } \\
\text { compounds }\end{array}$ & $\begin{array}{c}\mathrm{Ca}^{2+} \text { flux assay: } \\
0.06 \mathrm{~h} ; \mathrm{ROS} \\
\text { production: } 0.5 \mathrm{~h}\end{array}$ & no & $\begin{array}{l}\text { EOs activated human neutrophil } \mathrm{Ca}^{2+} \text { flux } \\
\text { this activation was dose-dependently } \\
\text { inhibited by capsazepine, a TRPV1 channel } \\
\text { antagonist. This effect was confirmed on } \\
\text { TRPV1 channel-transfected hEK293 cells. } \\
\text { Furthermore, EOs also activated } \\
\text { SOD-inhibitable ROS production in } \\
\text { both human neutrophils and mouse bone } \\
\text { marrow phagocytes. }\end{array}$ \\
\hline Park et al. [94] & $\begin{array}{l}\text { Murine macrophage } \\
\text { RAW264.7 cells }\end{array}$ & Chamaecyparis obtusa & $1,10,50$, and $100 \mu \mathrm{g} / \mathrm{mL}$ & $\begin{array}{c}\alpha \text {-terpinyl acetate, } \\
\beta \text {-phellandrene, } \\
\beta \text {-myrcene, } \\
\text { limonene, bornyl } \\
\text { acetate, } \\
\gamma \text {-terpinene, } \\
\beta \text {-thujaplicin, and } \\
\alpha \text {-terpineol }\end{array}$ & $1 \mathrm{~h}$ & yes $(1 \mu \mathrm{g} / \mathrm{mL})$ & $\begin{array}{l}\text { In LPS-stimulated cells, EOs treatment } \\
\text { reduced nitric oxide, TNF- } \alpha \text {, and IL-6 } \\
\text { production, and inhibited iNOS and COX-2 } \\
\text { expression. }\end{array}$ \\
\hline $\begin{array}{c}\text { Puskárova et al. } \\
\text { [57] }\end{array}$ & $\begin{array}{l}\text { human embryo } \\
\text { lung hEL12469 cells }\end{array}$ & $\begin{array}{l}\text { Origanum vulgare; } \\
\text { Thymus vulgaris; } \\
\text { Salvia sclarea; } \\
\text { Lavandula } \\
\text { angustifolia; Eugenia } \\
\text { caryophyllata; and } \\
\text { Thuja plicata }\end{array}$ & $0.0025-1.0 \mu \mathrm{L} / \mathrm{mL}$ & - & $24 \mathrm{~h}$ & no & $\begin{array}{l}\text { EOs present toxic side effects at higher } \\
\text { concentrations. Treatment with EOs did no } \\
\text { induce any significant increase in DNA } \\
\text { strand breaks; only Thuja plicata EO } \\
(0.2 \mu \mathrm{L} / \mathrm{mL}) \text { showed a negative effect on } \\
\text { DNA single-strand breaks in hEL } 1269 \text { cells }\end{array}$ \\
\hline
\end{tabular}


Table 4. Cont.

\begin{tabular}{|c|c|c|c|c|c|c|c|}
\hline Author & Cell Line & Plant Derived EOs & EOs Concentration & $\begin{array}{c}\text { Main } \\
\text { Components of } \\
\text { EOs }\end{array}$ & Exposure Time & LPS Stimulation & Main Results \\
\hline $\begin{array}{c}\text { Smeriglio et al. } \\
\text { [64] }\end{array}$ & $\begin{array}{l}\text { human blood isolated } \\
\text { lymphocytes } \\
\text { from healthy donors }\end{array}$ & Pistacia vera $\mathrm{L}$. & $\begin{array}{c}20,17.5,15,12.5,10,7.5 \\
5, \text { and } 1 \mu \mathrm{g} / \mathrm{mL}\end{array}$ & $\begin{array}{c}\text { 4-Carene, } \\
\alpha \text {-pinene, and } \\
\delta \text {-3-carene were } \\
\text { the major } \\
\text { compounds }\end{array}$ & $24 \mathrm{~h}$ & no & $\begin{array}{l}\text { EOs did not show any cytotoxic effects. In } \\
\text { tert-butyl hydroperoxide-treated } \\
\text { lymphocytes, incubation with EOs } \\
(20-12.5 \mu \mathrm{g} / \mathrm{mL}) \text { significantly increased cell } \\
\text { viability. }\end{array}$ \\
\hline Touihri et al. [68] & $\begin{array}{l}\text { human colonic } \\
\text { adenocarcinoma hT29-D4 } \\
\text { and Caco-2 cell lines }\end{array}$ & Allium roseum $\mathrm{L}$. & $10,20,30$, and $40 \mu \mathrm{g} / \mathrm{mL}$ & $\begin{array}{l}\text { Methyl } \\
\text { methanethiosulfinate, } \\
\text { 3-vinyl-1, } \\
\text { 2-dithiacyclohex-5-ene, } \\
\text { and diallyl } \\
\text { trisulfide were the } \\
\text { major compounds }\end{array}$ & $\begin{array}{l}\text { Cytotoxicity assay: } \\
5 \text { h; Proliferation } \\
\text { assay: } 72 \mathrm{~h}\end{array}$ & no & $\begin{array}{l}\text { EOs did not show cytotoxic effects. } \\
\text { Antiproliferative assay depicted that the } \\
\text { number of cells was reduced by the } \\
\text { incubation of hT29-D4 and Caco-2 cells with } \\
\text { EOs in a dose-dependent fashion. }\end{array}$ \\
\hline Ušjak et al. [69] & $\begin{array}{l}\text { human cervix hela } \\
\text { cell; human colon } \\
\text { carcinoma LS174 cell; } \\
\text { non-small cell lung } \\
\text { carcinoma A549; human } \\
\text { normal fetal lung } \\
\text { fibroblast MRC-5 cell }\end{array}$ & $\begin{array}{l}\text { Heracleum } \\
\text { pyrenaicum subsp. } \\
\quad \text { orsinii }\end{array}$ & $\begin{array}{c}12.5,25,50,100, \text { and } \\
200 \mu \mathrm{g} / \mathrm{mL}\end{array}$ & $\begin{array}{c}\beta \text {-pinene, } \\
\text { (Z)- } \beta \text {-ocimene, } \\
\text { and } \alpha \text {-pinene were } \\
\text { the major } \\
\text { compounds }\end{array}$ & $72 \mathrm{~h}$ & no & $\begin{array}{l}\text { The cytotoxic effect of EOs was prominent } \\
\text { against hLLa, LS174, and A549 cell lines. EOs } \\
\text { did not show toxicity side effects against } \\
\text { normal MRC- } 5 \text { cell }\left(\mathrm{IC}_{50}>200 \mu \mathrm{g} / \mathrm{mL} \text { ). }\right.\end{array}$ \\
\hline Wang et al. [95] & $\begin{array}{l}\text { Murine macrophage } \\
\text { RAW264.7 cells }\end{array}$ & Trachydium roylei & $\begin{array}{c}1.25,2.5,5.0,10 \text {, and } \\
20 \mathrm{mg} / \mathrm{mL}\end{array}$ & $\begin{array}{l}\beta \text {-phellandrene, } \\
\text { myristicin, and } \\
\text { elemicine were the } \\
\text { major compounds }\end{array}$ & $1 \mathrm{~h}$ & yes $(100$ ng/mL) & $\begin{array}{l}\text { In LPS-stimulated RAW264.7 cells, only } \\
\text { a high concentration of EOs ( } 40 \mathrm{mg} / \mathrm{mL}) \\
\text { showed a negative effect on cell viability. } \\
\text { In addition, incubation with EOs inhibited } \\
\text { the production of TNF- } \alpha \text {, IL-1 } 1 \beta \text {, and IL-6, } \\
\text { whereas it increased the release of IL-10. EOs } \\
\text { also inhibited the secretion of NO and PGE }\end{array}$ \\
\hline
\end{tabular}

Abbreviations: EO: essential oil; LPS: lipopolysaccharide; IL: interleukin; TNF- $\alpha$ : tumor necrosis factor alpha; NO: nitric oxide; iNOS: inducible nitric oxide synthase; MAPK:

mitogen-activated protein kinase; PKB: protein kinase B; NF-kB: nuclear factor kappa-light-chain-enhancer of activated B cells; COX-2: cyclooxygenase 2; PGE2: prostaglandin E2; ox-LDL:

oxidized low-density lipoprotein. 
Table 5. Main characteristics of studies related with immunomodulatory properties of essential oils in animals.

\begin{tabular}{|c|c|c|c|c|c|c|c|}
\hline Author & Animal & Plant Derived EOs & EOs Conce & $\begin{array}{l}\text { Main } \\
\text { Components of } \\
\text { EOs }\end{array}$ & $\begin{array}{c}\text { EOs } \\
\text { Administration }\end{array}$ & Treatment Duration & Main Results \\
\hline $\begin{array}{l}\text { Adaszynska- } \\
\text { Skwirzynska } \\
\text { et al. [96] }\end{array}$ & Broiler chickens & $\begin{array}{l}\text { Lavandula } \\
\text { angustifolia }\end{array}$ & $0.4 \mathrm{~mL} / \mathrm{L}$ & $\begin{array}{l}\text { Linalool and linalool acetate were } \\
\text { the major compounds }(>80 \%)\end{array}$ & $\begin{array}{l}\text { Drinking water } \\
\text { (6 h/day) }\end{array}$ & $\begin{array}{l}\text { From } 1 \text { to } 42 \mathrm{~d} \text { of age and } \\
\text { from } 22 \text { to } 42 \mathrm{~d} \text { of age }\end{array}$ & $\begin{array}{l}\text { Broiler chickens treated with EO } \\
\text { weighed an average of } 6.35 \% \text { more } \\
\text { than those in the control group. No } \\
\text { differences were found in feed and } \\
\text { water intake, survival rate, or } \\
\text { biochemical parameters. EOs intake } \\
\text { also has an impact on ileum } \\
\text { gastrointestinal microbiota } \\
\text { (pathogenic microorganisms } \\
\text { decreased, while the number of } \\
\text { probiotic bacteria increased). }\end{array}$ \\
\hline Altop et al. [97] & Broiler chickens & Liquidambar & $\begin{array}{l}0.0405,0.0811 \text {, and } \\
0.1622 \mathrm{~g} / \mathrm{kg}\end{array}$ & $\begin{array}{l}\gamma \text {-Terpinen, terpinen-4-ol, and } \\
\alpha \text {-terpinene were the major } \\
\text { compounds }\end{array}$ & $\begin{array}{l}\text { Basal diet } \\
\text { supplemented } \\
\text { (ad libitum) }\end{array}$ & $42 \mathrm{~d}$ & $\begin{array}{c}\text { Treatment with EOs, mainly at } \\
0.0811 \mathrm{~g} / \mathrm{kg} \text { concentration, improved } \\
\text { growth performance and carcass traits } \\
\text { while reducing blood cholesterol } \\
\text { levels and E. coli counts. }\end{array}$ \\
\hline Cetin et al. [98] & Broiler chickens & $\begin{array}{l}\text { Origanum sp, } \\
\text { Rosmarinus officinalis } \\
\mathrm{L} \text { and Foeniculum } \\
\text { vulgare } \mathrm{L} \text {. }\end{array}$ & $\begin{array}{l}\text { Individual EO: } \\
100 \mathrm{mg} / \mathrm{kg} . \text { EO } \\
\text { mixture: } 100,200 \\
\text { and } 400 \mathrm{mg} / \mathrm{kg}\end{array}$ & $\begin{array}{l}\text { Rosemary oil, 1,8-cineol, } \alpha \text {-pinene, } \\
\text { and camphene; oregano oil, } \\
\text { carvacrol; and fennel oil, } \\
\text { trans-anethole, and fenchone }\end{array}$ & $\begin{array}{l}\text { Basal diet } \\
\text { supplemented } \\
\text { (ad libitum) }\end{array}$ & $42 \mathrm{~d}$ & $\begin{array}{l}\text { Dietary supplementation increased the } \\
\text { body weight of broilers at } 7,14, \text { and } 21 \\
\mathrm{~d} \text { of age. The blend of EO at } 400 \mathrm{mg} / \mathrm{kg} \\
\text { significantly increased Lactobacillus } \\
\text { spp. in feces, and also exhibited } \\
\text { stronger antibacterial activity against } \\
\text { coliform bacteria. }\end{array}$ \\
\hline Chen et al [89] & C57BL/6 mouse & Litsea cubea $\mathrm{L}$. & $\begin{array}{l}\text { 50- and 100-fold } \\
\text { diluted }\end{array}$ & $\begin{array}{l}\text { Terpene aldehydes }(75.09 \%) \text { were } \\
\text { the most abundant compounds }\end{array}$ & $\begin{array}{l}\text { Abdomens were } \\
\text { painted }\end{array}$ & $5 \mathrm{~d}$ & $\begin{array}{l}\text { Treatment with EO showed an } \\
\text { inhibitory effect on } \\
\text { contact hypersensitivity response. }\end{array}$ \\
\hline Chen et al. [22] & C57BL/6 mouse & Artemisia argyi & $\begin{array}{l}750,250 \text {, and } \\
83 \mathrm{mg} / \mathrm{kg}\end{array}$ & $\begin{array}{l}\text { Cineole, camphor, (-)-borneol, and } \\
\alpha-(-) \text {-thujone were the major } \\
\text { compounds }\end{array}$ & $\begin{array}{c}\text { Oral } \\
\text { administration }\end{array}$ & $\begin{array}{l}30 \text { minutes before } \\
\text { 12-O-tetradeconoylphorbol } \\
\text {-13-acetate application }\end{array}$ & $\begin{array}{c}\text { Oral administration of the EO } \\
\text { significantly attenuated TPA-induced } \\
\text { mouse ear edema and decreased the } \\
\text { protein level of COX-2 }\end{array}$ \\
\hline $\begin{array}{l}\text { Gomes Cairo } \\
\text { et al. [99] }\end{array}$ & Weaned pigs & $\begin{array}{c}\text { Schinus } \\
\text { terebinthifolius Raddi }\end{array}$ & $0.5,1.0$, and $1.5 \mathrm{~g} / \mathrm{kg}$ & $\begin{array}{l}\delta \text {-3-carene, } \alpha \text {-phellandrene, } \\
\text { limonene, and } \alpha \text {-pinene were the } \\
\text { major compounds }\end{array}$ & $\begin{array}{l}\text { microencapsulated } \\
\text { product }\end{array}$ & $14 \mathrm{~d}$ & $\begin{array}{l}\text { EO treatment modulated the } \\
\text { gastrointestinal microbiota by } \\
\text { increasing Lactobacillus and reducing } \\
\text { enterobacteria counts. Growth } \\
\text { performance was not affected by EO } \\
\text { treatment, although EO }(1.5 \mathrm{~g} / \mathrm{kg}) \text { can } \\
\text { reduce diarrhea incidence. }\end{array}$ \\
\hline
\end{tabular}


Table 5. Cont

\begin{tabular}{|c|c|c|c|c|c|c|c|}
\hline Author & Animal & Plant Derived EOs & EOs Conce & $\begin{array}{l}\text { Main } \\
\text { Components of } \\
\text { EOs }\end{array}$ & $\begin{array}{c}\text { EOs } \\
\text { Administration }\end{array}$ & Treatment Duration & Main Results \\
\hline Li et al. [100] & Weaned piglets & $\begin{array}{l}\text { Carvacrol and } \\
\text { thymol }\end{array}$ & $\begin{array}{l}\text { Carvacol: } \\
62.5 \mathrm{mg} / \mathrm{kg} ; \text { Thymol: } \\
7.5 \mathrm{mg} / \mathrm{kg}\end{array}$ & $\begin{array}{c}\mathrm{N} \text {-(2-hydroethyl)-iminodiacetic acid } \\
2\end{array}$ & $\begin{array}{c}\text { Basal diet } \\
\text { supplemented } \\
\text { (ad libitum) }\end{array}$ & $30 \mathrm{~d}$ & $\begin{array}{l}\text { EO treatment significantly increased } \\
\text { the relative abundance of Bacillli, } \\
\text { Lactobacillales, Streptocpccaceae and } \\
\text { Veillonellaceae in colonic samples. } \\
\text { Metabolomics analysis showed that } \\
\text { protein biosynthesis, amino acid } \\
\text { metabolism, and lipid metabolisms } \\
\text { were enriched in the EO group. }\end{array}$ \\
\hline Park et al. [94] & $\begin{array}{l}\text { Carrageenan- } \\
\text { induced paw } \\
\text { edema model } \\
\text { (C57BL/6) and } \\
\text { thioglycollate- } \\
\text { induced } \\
\text { peritonitis } \\
\text { model } \\
(\mathrm{C} 57 \mathrm{BL} / 6) \\
\end{array}$ & Chamaecyparis obtusa & 5 and $10 \mathrm{mg} / \mathrm{kg}$ & $\begin{array}{c}\alpha \text {-terpinyl acetate, } \beta \text {-phellandrene, } \\
\beta \text {-myrcene, limonene, bornyl } \\
\text { acetate, } \gamma \text {-terpinene, } \beta \text {-thujaplicin, } \\
\text { and } \alpha \text {-terpineol }\end{array}$ & $\begin{array}{l}\text { Intraperitoneal } \\
\text { administration }\end{array}$ & $\begin{array}{c}1 \mathrm{~h} \text { prior to } \\
\text { inflammation-induced } \\
\text { treatment }\end{array}$ & $\begin{array}{l}\text { EO treatment reduced the levels of } \\
\text { IL- } 6 \text { and IL- } 1 \beta \text { in paw homogenates } \\
\text { and in peritoneal fluid. In } \\
\text { thioglycollate-induced peritonitis } \\
\text { levels of TNF- } \alpha \text { in peritoneal fluid. }\end{array}$ \\
\hline Sutili et al. [101] & Silver catfish & $\begin{array}{l}\text { Hesperozygis ringes, } \\
\text { Ocimun gratissimum, } \\
\text { and Ocimun } \\
\text { americanum }\end{array}$ & $\begin{array}{l}\text { Hesperozygis ringes: } \\
20 \text { and } 40 \mathrm{mg} / \mathrm{L} ; \\
\text { Ocimun gratissimun: } \\
5 \text { and } 10 \mathrm{mg} / \mathrm{L} ; \\
\text { Ocimum americanun: } \\
10 \text { and } 20 \mathrm{mg} / \mathrm{L}\end{array}$ & $\begin{array}{l}\text { H. ringens, pulegone; O. gratissimum, } \\
\text { eugenol; O. americanum, } 1.8 \text {-cineole, } \\
\beta \text {-linalool, eugenol, and camphor }\end{array}$ & Daily bath for & $1 \mathrm{~h}$ during $5 \mathrm{~d}$ & $\begin{array}{l}\text { Fish exposed to EOs showed } \\
\text { significant lower hematocrit values } \\
\text { and higher complement system } \\
\text { activity and plasma cortisol levels. } \\
\text { There was no significant difference in } \\
\text { the survival of fish challenged with } \\
\text { Aeromonas hydrophila. }\end{array}$ \\
\hline Yang et al. [23] & Weaned piglets & $\begin{array}{l}\text { Mixture of EOs and } \\
\text { organic acids: } \\
\text { cinnamaldehyde } \\
(15 \%) \text {, thymol }(5 \%), \\
\text { citric acid }(10 \%), \\
\text { sorbic acid }(10 \%), \\
\text { malic acid }(6.5 \%) \\
\text { and fumaric acid } \\
(13.5 \%)\end{array}$ & $1 \mathrm{~kg} / \mathrm{ton}$ & & $\begin{array}{l}\text { Basal diet } \\
\text { supplemented } \\
\text { (ad libitum) }\end{array}$ & $28 \mathrm{~d}$ & $\begin{array}{l}\text { Diet supplementation with the } \\
\text { mixture improved the final body } \\
\text { weight and average daily gain, } \\
\text { increased the concentration of serum } \\
\text { complement 4, and enhanced the } \\
\text { isovaleric acid fecal concentration. } \\
\text { Regarding the gastrointestinal } \\
\text { microbiota composition in fecal } \\
\text { samples, the mixture treatment } \\
\text { increased the beta diversity. }\end{array}$ \\
\hline
\end{tabular}

Abbreviations: EO, essential oil; d: days; TNF- $\alpha$ : tumor necrosis factor alpha; TPA: 12-O-tetradeconoylphorbol-13-acetate; COX-2: ciclooxigenase 2. 


\section{Discussion}

There is a huge amount of different EOs from different plants around the world. Most of them have been shown to exert a well-characterized antimicrobial activity against Gram-positive and Gram-negative bacteria, but also against other microorganisms, such as yeast. The irreversible damage of the bacterial cell wall and membrane has been proposed as its main mechanisms of action. In addition, several studies revealed how EOs can inhibit biofilm formation through the inhibition of bacterial cell communication. Regarding their antioxidant and immunomodulatory properties, EOs have been shown to exert a protective effect through their radicals scavenging activity, with an inhibition percentage range of $20 \%-70 \%$, and their effect against DNA oxidative damage induced by $\mathrm{Fe}^{2+}$. Regarding their immunomodulatory effect, EOs or their main compounds can modulate the secretion of important cytokines in a cell culture challenge with LPS. This capacity was evident in their effect in inflammatory pathways such as nuclear factor kappa-light-chain-enhancer of activated B cells (NF-kB). It is important to highlight that a cytotoxic effect was not observed when EOs where used at low concentrations. There have been a few studies in poultry animals where EOs have a positive effect on growth parameters; however, on the gastrointestinal microbiota, EOs have a negative affect on gastrointestinal pathogen microorganisms. Their biological properties can be attributed to their complex composition with more than 300 different volatile compounds. These volatile compounds include terpenes, alcohols, phenolic acids, ethers, esters, amines, amides, ketones, and aldehydes, among other chemical components [102]. Although most of their biological actions have been related to their main components, it is important to underpin that the aforementioned properties come over the synergic effect of all the components. The results from this review indicate that EOs have important biological properties that make them suitable for use in the development of functional foods. however, in this regard, one aspect that must be considered is their strong smell, which could result in low acceptance by the consumer or modification of the organoleptic properties of the food [8].

\subsection{Antimicrobial Activity of Esential Oils}

In recent years, there has been a growing interest in researching and developing new antimicrobial agents from EOs due to drug resistance in foodborne bacterial enteric pathogens. Numerous publications have presented data on the antimicrobial properties of EOs [29,30].

A variety of laboratory methods can be used to evaluate the in vitro antimicrobial activity of an EO. The most well-known and basic methods are the disk diffusion and broth or agar dilution methods [103]. The lowest concentration of antimicrobial agent that completely inhibits the growth of the organism is called the minimum inhibitory concentration (MIC). The most appropriate assays for the determination of the MIC value are the dilution methods, as they offer the possibility of a precise estimation of the concentration of the tested antimicrobial agent.

The antibacterial effects based on the MIC determination of several EOs alone or in combination against different food-associated Gram-positive and Gram-negative bacteria have been described. Parsley, lovage, basil, and thyme are a few of the aromatic herbs commonly used in industry with low-cost production. Different parts of these herbs (leaves, flowers, stems, fruits, and seeds) have been used to extract EOs [60]. Parsley and lovage EOs revealed no inhibitory effects against all tested strains. Thyme EO had the highest percentage yield and antibacterial potential from all tested formulations; its use in combination with parsley, lovage, and basil EOs results in a reduction in its antibacterial activity; therefore, thyme EO should be used alone [60]. EOs of cultivated oregano (Origanum vulgare), sage (Salvia officinalis), and thyme (Thymus vulgaris) have been shown to exert a potent antimicrobial effect. Among them, the most efficient were the EOs from thyme, followed by those of oregano. With MIC values above $150 \mathrm{mg} / \mathrm{mL}$, sage EOs did not show any antibacterial effect against the majority of the bacterial strains [38]. Three Origanum species analyzed, O. dictamnus and O. microphyllum-both endemic in Greece-and O. libanoticum, endemic in Lebanon, were evaluated, but only O. dictamnus exerted antibacterial activity [46]. 
Different bacterial and fungal strains have been used to determine the antibacterial effects of different Eos; these microorganisms comprise strains from Staphylococcus, Bacillus, Listeria, Helicobacter, Micrococcus, Pseudomonas, Klepsiella, Escherichia, Salmonella, Enterobacter, and Candida. EOs from Heracleum pyrenaicum subsp. orsinii, Pistacia vera L., Myrcia ovata Cambessedes, Thymus bovei, Minthostachys verticillata, Allium roseum, Petroselinum crispum, Satureja bachtiarica Bunge, Ocimum suave, Jatropha gossypifolia L., and Juniperus rigida have been shown to exert antibacterial and anti-yeast effects $[34,37,41,43,47,48,51,64,67-69]$. One of the proposed mechanisms for those effects is the irreversible damage of the bacteria cell wall and membrane, which leads to not only a leakage of proteins but also of DNA and RNA molecules $[47,48]$.

Enteromorpha linza, Baccharis dracunculifolia, Syringa yunnanensis, Senecio nutans, basil, chamomile blue, oregane, thyme, tea tree oil, Carum copticum, and Xanthium strumarium L. EOs have also been described for their anti-microorganism effects against several bacteria, fungi, and even some pathogens, such as Vibrio cholerae. Specifically, Enteromorpha linza EO is effective against B. cereus and S. aureus [54], Baccharis dracunculifolia EO is active against S. aureus and E. coli [55], Senecio nutans EO is effective against $V$. cholerae [53], Syringa yunnanensis EO is effective against $S$. aureus [72], Carum copticum EO is capable of reducing the growth of E. coli O157:H7 [44], and Xanthium strumarium L. EO is also effective against $S$. aureus, B. subtilis, K. pneumoniae, P. aeruginosa, C. albicans, and A. niger [63]. In contrast, basil, chamomile blue, oregane, thyme, and tea tree oil EOs were not sufficiently effective against A. baumannii, E. coli, K. pneumoniae, and P. aeruginosa [58].

EOs from plants from different regions of the world have been studied. In this sense, EOs derived from Aloysia citriodora Palau, which is harvested in different regions of Morocco, showed significant antimicrobial activity against both Gram-negative and Gram-positive bacteria [52]. The EOs of Peperomia pellucida, an herbaceous plant from the Amazon region, exhibited strong antibacterial activities against six different bacteria strains [50]. Salem et al. evaluate the biological activity of the EOs derived from Corymbia citriodora leaves and Cupressus macrocarpa from Egypt. While the antibacterial activity of EO from C. citriodora leaves has MIC values ranging from 0.06 to $0.20 \mathrm{mg} / \mathrm{mL}$, EO from C. macrocarpa branchlets showed less activity against bacterial strains [59].

In recent years, there has been a dramatic increase in resistance to antimicrobial drugs against Salmonella Enterica and Campylobacter spp. Campylobacter spp. is one of the most common causative agents of gastroenteritis in the world, whereas salmonellosis is a major foodborne disease worldwide. Bacteria can be transmitted to humans by the consumption of contaminated poultry, eggs, beef, milk, juices, fruits, and vegetables. Several studies have shown that EOs could be used as alternative therapeutics to treat antibiotic-resistant Salmonella. In this regard, Ruilopezia bracteosa EO has been described as being effective against $S$. aureus and E. faecalis compared with several antibiotics [26]. Similarly, Ashraf et al. studied the effect of Nigella sativa (Black seed) oil against antibiotic-resistant isolates by a well diffusion and microbroth dilution method, and they concluded that N. sativa had in vitro activity against Salmonella Enterica [27]. Chiboub et al. evaluated the biological activity of the EOs of two varieties of Foeniculum vulgare in the growth of Salmonella Enterica, and the results showed a significant antimicrobial activity [32]. Aghraz et al. showed that EOs from Cladanthus arabicus and Bubonium imbricatum contain a potent activity against the tested Salmonella strain, with MIC values between 200 and $800 \mu \mathrm{g} / \mathrm{mL}$ for C. arabicus and from 400 to $1600 \mu \mathrm{g} / \mathrm{mL}$ for B. imbricatum [25]. The evaluation of the synergistic effect of mixed EOs was also investigated. To increase the sensitivity against the Salmonella Typhimurium strain, a mixture of Thymus vulgaris L., Rosmarinus officinalis L., and Myrtus communis $\mathrm{L}$ was used. EOs were used in combined treatment using an experimental design methodology [36]. A mixture of $55 \%$ of T. vulgaris L. and $45 \%$ of $M$. communis L. EOs, respectively, can be considered for the increase of Salmonella Typhimurium sensitivity. Mutlu-Ingok et al. studied the antibacterial activities of cardamom, cumin, and dill weed EOs against Campylobacter jejuni and Campylobacter coli. The results indicated that EOs might be effective inhibitors by directly acting at the bacterial membrane integrity level [49]. It is important to highlight that EOs derived from oregano, 
thyme, clove, and arborvitae also showed a very strong antibacterial activity against other bacteria causing foodborne disease; therefore, they can be used as antimicrobial agents [57].

One important concern in the food industry is the presence of biofilms. Bacteria can be suspended in liquid food, usually living planktonically, although they can easily adhere to the surface of food materials and food processing equipment, forming a bacterial biofilm. Biofilms are microbial communities that are characterized by their adhesion to solid surfaces and the production of a matrix of exopolymeric substances; the matrix consists of polysaccharides, proteins, DNA, and lipids, which surround the microorganisms, proffering structural integrity and a unique biochemical profile to the biofilm [104]. Biofilms can exist on all types of surfaces in food plants ranging from plastic, glass, metal, and wood, to food products [105], resulting in food spoilage and economic losses for the producers [105]. Several studies revealed how EOs can inhibit biofilm formation [33,56,62,65,71]. Cinnamomum zeylanicum oil may be a useful approach to impair the biofilm produced by Gram-negative bacteria [33]. According to Porfirio et al., Lippia Alba EOs have a strong inhibition of S. aureus biofilm formation [56]. Likewise, EOs derived from parsley and basilic can inhibit and eradicate the mature biofilm formed by Vibrio strains on a polystyrene surface even at low concentrations. These two EOs could be used to prevent and eradicate the contamination of sea products by these strains [65]. It has been described that quorum sensing (QS), the process through which bacterial cells communicate with each other by releasing, sensing, and responding to small diffusible signal molecules [106], is involved in biofilm formation. QS has been inhibited by the EOs of several plants, such as Thymus daenensis and Satureja hortensis. Consequently, EOs act as anti-biofilm and QS inhibitor agents against bacteria [62].

\subsection{Antioxidant Activity of Essential Oils}

The excessive amounts of reactive oxygen species (ROS) can lead to the peroxidation of lipids, glycation/oxidation/nitration of proteins, inactivation of enzymes, DNA damage, and other alterations in the cellular organelles $[107,108]$.

In recent years, food oxidation and food spoilage caused by microorganisms form one of the most important issues facing the food industry and consumers. Accompanied by growing consumer interest in natural food additives, the search for effective antioxidants and antibacterial agents from natural resources as alternatives to suppress food deterioration is now focused on edible plants, since they present with fewer side effects than the synthetic chemicals used in today's foods [109]. There has been an increasing realization in recent years that several plant-derived EOs may possess antioxidant, antimicrobial, anticancer, and apoptosis-inducing properties [110].

Cyperus rotundus $\mathrm{L}$. is a smooth and perennial weed that is widely distributed in tropical and warmer temperate regions worldwide [77]. The antioxidant properties of the C. rotundus rhizome were determined. In addition, 1,1-diphenyl-2-picrylhydrazyl (DPPH) and 2,2'-azino-bis(3-ethylbenzothiazoline-6-sulphonic acid) (ABTS) radicals scavenging activity, ferric-reducing antioxidant power (FRAP), and oxidative DNA damage protective effect induced by $\mathrm{Fe}^{2+}$ and 2,2' -azobis (2-methylpropionamidine) dihydrochloride (AAPH) were also determined. C. rotundus rhizomes possessed an excellent antioxidant activity, as evidenced by in vitro DPPH, ABTS, and FRAP assays. In addition, EOs exhibited a protective effect against DNA oxidative damage induced by $\mathrm{Fe}^{2+}$ and $\mathrm{AAPH}$, respectively [77].

An antioxidant combination effect of bay leaf, black pepper, coriander (seed and leaf), cumin, garlic, ginger, mustard, onion, and turmeric EOs was assessed by the DPPH free radical scavenging method. Only the coriander/cumin seed oil combination exhibited antioxidant activity in a synergistic interaction. Bioactive compounds responsible for this antioxidant capacity were linalool from coriander seed oil and p-coumaric acid from cumin seed oil [74]. DPPH radical scavenging activity assay, $\beta$-carotene bleaching test (BCBT), and ABTS assay were determined in Melissa officinalis and Dracocephalum moldavica EOs. Both EOs showed a strong activity in terms of the maintenance of $\beta$-carotene molecules. The ABTS radical scavenging of the EOs was dose-dependent and increased with the increase in the EOs concentration [76]. The antioxidant activity of the EO of Ruta chalepensis was tested by DPPH 
using Trolox as a reference compound. Percentages of inhibition for $R$. chalepensis collected from Jerusalem, hebron, and Jenin were $69.56 \%, 61.53 \%$, and $24.12 \%$, respectively [78]. Achillea millefolium L., Anethum graveolens L., and Carum copticum L. EOs were selected to evaluate their antioxidant properties using DPPH, FRAP, BCBT, and total phenolic content assays. A. millefolium EO had the highest antioxidant activity in all conducted assays [79]. With a similar methodology, Foeniculum vulgare, Petroselium crispum, and Lavandula officinalis EOs, six different populations of Origanum heracleoticum L. from Calabria (Italy) Eos, and Pelargonium asperum and Ormenis mixta were analyzed. Petroselium crispum had the highest phenolic content and the best antioxidant profile [80], EO samples from Bagaladi and Longobucco were the most active in DPPH and BCBT assays [81], and only Ormenis mixta EO displayed an effective antioxidant ability, as tested by DPPH assay [83].

The antioxidant properties of EOs from the fruits Dennettia tripetala G. Baker as ripe and unripe fruit oil were tested. The ripe fruit EO has shown higher antioxidant strength than unripe fruit EO and vitamin C, but a lower activity compared to BCBT. The EOs also demonstrated strong ability in terms of scavenging three other different radicals (ABTS, lipid peroxide, and nitric oxide radicals) in a concentration-dependent manner [82]. With a similar methodology, Jatropha gossypifolia L and Peperomia pellucida (L.) Kunth were tested. The EOs effectively reduced oxidants to neutral molecules in a concentration-dependent manner [50,51].

Ferulago angulata-collected from natural habitats in the alpine regions of southwestern Iran-balsam fir (Abies balsamea (L.) Mill.), black spruce (Picea mariana (Mill.) B.S.P.), white spruce (Picea glauca (Moench) Voss), tamarack (Larix laricina (Du Roi) K. Koch), jack pine (Pinus banksiana Lamb.), eastern white cedar (Thuja occidentalis L.), Labrador tea (Ledum groenlandicum L.), Mentha spicata EOs, and the EO of the Pistacia vera L. variety Bronte were analyzed using DPPH assay. The highest antioxidant activity was obtained from the EO of the Kallar population [84]; in contrast, balsam fir, black spruce, white spruce, tamarack, and eastern white cedar oils again exhibited very poor antioxidant activities [85]. The antioxidant ability of the spearmint oil was $3 \mu \mathrm{g} / \mathrm{mL}$, in comparison to $11.5 \mu \mathrm{g} / \mathrm{mL}$ for the standard compound. This interesting biological activity can be explained by the presence of the monoterpenes limonene, terpinolene, $\gamma$-terpinene, 1,8 -cineole, and carvone in the EO [88]; the Pistacia vera L. variety Bronte showed little affect against the DPPH test [64].

The antioxidant properties of aerial parts of Glycyrrhiza triphylla Fisch. and CA Mey and parsley, lovage, basil, and thyme EOs were investigated with DPPH and BCBT assays. G. triphylla EO exhibited a high antioxidant activity only in terms of the DPPH radical scavenging activity [87]. Parsley and lovage had a weak antioxidant activity, whereas basil showed a moderate antioxidant activity. Finally, thyme EO showed the highest antioxidant capacity [86].

Bergamot and lemon EOs extracted from the fruit peel of several citrus varieties were analyzed to determine their antioxidant activity through a thiobarbituric acid reactive substances (TBARS) test in a fish model (sardine). Samples of sardine treated with the bergamot EO displayed greater antioxidant activity than lemon EO [75].

\subsection{Immunomodulatory Activity Effects of Essential Oils in Cells and Animals}

Inflammation is a complex immune response against different types of harmful factors. Pathogenic microorganisms, irritants compounds, or damaged tissue induce an acute inflammatory response that can persist for a short period of time, which is beneficial for the host. In spite of this, if resolution of the inflammation is not adequate or the stimulus persists, then it is called chronic inflammation, which predisposes the hosts to different diseases such as cancer, cardiovascular disease, neurological disease, and metabolic disorders. During a chronic inflammation response, different signaling pathways are activated, leading to the overexpression of pro-inflammatory genes and proteins such as the NF- $\kappa B$ transcription factor and cytokines including IL and TNF- $\alpha$. This inflammation is also related to an increased release and accumulation of ROS and reactive nitrogen species (RNS). When ROS production is greater than the cellular antioxidant capacity, oxidative stress can harm lipids, proteins, 
and DNA [111]. In this sense, EOs are of the greatest interest because of their anti-inflammatory and antioxidant properties, which are a potential source for the development of functional foods.

In general, EOs did not produce any cytotoxic effect when they were used at low concentrations; indeed, in human blood-isolated lymphocytes from healthy donors, Pistacia vera L. EOs significantly increased cell viability [64]. however, a high dose can have a negative effect on cell viability. In the case of malignant cells, it has been described that EOs derived from Heracleum pyrenaicum subsp. orsinii inhibited cell growth, which is in agreement with the established criteria from the National Cancer Institute (NCI), whereas they showed no toxic side effects on normal MRC-5 cells [69]. In line with these results, Pituranthos tortuosus EO is able to inhibit cell proliferation in a concentration-dependent and time-dependent manner on B16F10 melanoma cancer cells, which is likely by an increased apoptotic pathway [91]. Likewise, in human colonic adenocarcinoma cancer cell lines (HT29-D4 and Caco-2 cell), Allium roseum L. EO has a growth-inhibitory effect in a dose-dependent manner, without being cytotoxic. This effect has been attributed to the presence of sulfurous compounds as the major constituents of this EO [68]. Conversely, Cirsium japonicum DC EOs could promote cell proliferation in the human pulmonary adenocarcinoma A549 cell line [92].

On the other hand, in LPS-stimulated murine macrophage RAW264.7 cells, treatment with EOs derived from Trachydium roylei, Artemisia argyi, and Chmaecyparis obtusa has been shown to inhibit the secretion of pro-inflammatory cytokines, whereas treatment with EOs derived from Trachydium roylei also increased the secretion of IL-10, which is an anti-inflammatory cytokine. Therefore, the regulation of cytokines in this cell model may be one of the mechanisms by which EOs have an anti-inflammatory effect $[22,90,94,95]$. In the case of Artemisia argyri EOs, the regulation of NF- $\mathrm{kB}$ and AP-1 translocation has been proposed as a possible mechanism for its anti-inflammatory effect. In addition, a significant phosphorylation of JAK2 and STAT1/3 was also observed, but not the activation of NF- $\mathrm{KB}$ and mitogen-activated protein kinase (MAPK) cascades [22]. Other important mediators in inflammation are the production of nitric oxide (NO), secretion of prostaglandin E2 (PGE2), and the production of ROS. EOs have been shown to affect the expression of inducible nitric oxide synthase (iNOS) and cycloxygenase-2 (COX-2) expression; therefore, they might affect the secretion of NO and PGE2. In line with this, Artemisia argyri and Trachydium roylei EOs have been described to alter iNOS and COX-2 gene and protein expression, and to inhibit NO and PGE2 secretion and ROS production [22,95]. In immune human cells, there are studies showing that EOs exert their anti-inflammatory effects through the regulation of cytokine secretion and ROS production [31,93].

Similarly, in C57BL/6 mice, treatment with EOs has been shown to be efficient in reducing the levels of pro-inflammatory mediators $[89,94]$. In the contact hypersensitivity response, treatment with Litsea cubea L. EOs was able to inhibit the immune response [89]. In one interesting article, Sutili et al. described the use of Hesperozygis ringes and Ocimun americamun in silver catfish exposed to Aeromonas hydrophila, where this EO significantly decreases the hematocrit values and increases the plasma cortisol level and complement system activity. These results indicated a potential use of EOs in the treatment of infected fish [101].

One possible use of EOs is in poultry production as a supplement in the diet to improve production and to decrease the use of antibiotics. Their use in broiler chicken has been shown to improve animal growth. One interesting point is the effect of EOs in gastrointestinal microbiota composition, where supplementation with them has been shown to exert a positive effect-decreasing the pathogenic microorganism while increasing the number of probiotic bacteria such as Lactobacillus spp. [96-98]. Correspondingly, in weaned piglets, EOs or their main active compounds positively modulated gastrointestinal microbiota $[23,99,100]$. In addition, the use of carvacrol and thymol enriched protein biosynthesis, amino acids, and lipid metabolism [100].

Owing to this, EOs could be useful to inhibit pathogenic bacteria without affecting gastrointestinal commensal bacteria. Using static batch culture systems inoculated with human feces, Thapa el al. have shown that several EO compounds selected for their effectiveness against gastrointestinal pathogen need not have a toxic outcome on commensals bacteria at concentrations that would probably suppress 
pathogen bacterial growth. In this regard, the relative proportion of bifidobacteria was increased, while Bacteroidetes and Clostridium clusters IV and XIVa were not significantly affected. In terms of fermentation, except for high concentrations of thymol and geraniol, the essential oil compounds had no effects [112].

\section{Conclusions}

EOs have important antimicrobial and immunomodulatory properties that make them suitable for food preservation, alternatives to antibiotics, and ingredients in functional foods. In this regard, antimicrobial activity was tested in several strains with a wide range of observed results; the inhibition of S. aureus and even $V$. cholerae and C. albicans has been reported. Some EOs have demonstrated their efficacy against several foodborne pathogens in vitro and model food systems, and they can be applied in foods to improve their microbiological safety; however, these aforementioned results cannot be always extrapolated. One important effect of EOs is their antioxidant properties, with a dose range between 0.01 and $10 \mathrm{mg} / \mathrm{mL}$. The EOs have demonstrated remarkable antioxidant activities, which can also be attributed to their richness in terms of phenolic derivatives.

Concerning their immunomodulatory effect, most of the articles highlighted that EOs did not produce a cytotoxic effect when they are used at low concentrations. Their immunomodulatory activity can be attributed to their ability to modify the secretion of cytokines, which is probably through the regulation of NF- $\mathrm{KB}$, but also through the MAPK signaling pathway, or through their ability to affect the cellular expression of iNOS and the secretion of prostaglandins.

Although the biological properties of EOS have been studied, there is a need for more well-designed studies, involving a normalization of dose and incubation time in cell and animal models that will allow gaining a better understanding of their biological activities and underlying mechanisms. Well-designed studies in animals and humans are compulsory to evaluate the efficacy of EOs.

Author Contributions: All authors participated in the bibliographic search, discussion, and writing of the manuscript.

Funding: Part of the research currently in progress in the authors' laboratory is funded by the company PAYMSA, S. A. through the grant \#4501 managed by the Fundacion General Empresa-Universidad de Granada.

Acknowledgments: Carolina Gomez-Llorente, Julio Plaza-Díaz and Angel Gil are part of the "UGR Plan Propio de Investigación 2016" and the "Excellence actions: Unit of Excellence on Exercise and health (UCEES), University of Granada".

Conflicts of Interest: The authors declare no conflict of interest.

\section{References}

1. Singh, R.L.; Mondal, S. Current Issues in Food Safety With Reference to human health. In Food Safety and human health; Elsevier: Amsterdam, The Netherlands, 2019; pp. 1-14.

2. Fung, F.; Wang, H.S.; Menon, S. Food safety in the 21st century. Biomed. J. 2018, 41, 88-95. [CrossRef] [PubMed]

3. Sezgin, A.C.; Ayyıld1z, S. Food additives: Colorants. In Science within Food: Up-to-Date Advances on Research and Educational Ideas; Formatex Research Center: Badajoz, Spain, 2017.

4. Bouarab Chibane, L.; Degraeve, P.; Ferhout, H.; Bouajila, J.; Oulahal, N. Plant antimicrobial polyphenols as potential natural food preservatives. J. Sci. Food Agric. 2019, 99, 1457-1474. [CrossRef] [PubMed]

5. van den Bogaard, A.E.; Stobberingh, E.E. Epidemiology of resistance to antibiotics: Links between animals and humans. Int. J. Antimicrob. Agents 2000, 14, 327-335. [CrossRef]

6. Rico-Campa, A.; Martinez-Gonzalez, M.A.; Alvarez-Alvarez, I.; Mendonca, R.D.; de la Fuente-Arrillaga, C.; Gomez-Donoso, C.; Bes-Rastrollo, M. Association between consumption of ultra-processed foods and all cause mortality: SUN prospective cohort study. BMJ 2019, 365, 11949. [CrossRef]

7. Calo, J.R.; Crandall, P.G.; O'Bryan, C.A.; Ricke, S.C. Essential oils as antimicrobials in food systems-A review. Food Control 2015, 54, 111-119. [CrossRef] 
8. Chouhan, S.; Sharma, K.; Guleria, S. Antimicrobial activity of some essential oils-Present status and future perspectives. Medicines 2017, 4, 58. [CrossRef] [PubMed]

9. Kon, K.V.; Rai, M.K. Plant essential oils and their constituents in coping with multidrug-resistant bacteria. Expert Rev. Anti-Infect. Ther. 2012, 10, 775-790. [CrossRef]

10. Bakkali, F.; Averbeck, S.; Averbeck, D.; Idaomar, M. Biological effects of essential oils-A review. Food Chem. Toxicol. 2008, 46, 446-475. [CrossRef]

11. Zhang, Q.W.; Lin, L.G.; Ye, W.C. Techniques for extraction and isolation of natural products: A comprehensive review. Chin. Med. 2018, 13, 20. [CrossRef]

12. Stratakos, A.C.; Koidis, A. Methods for extracting essential oils. In Essential Oils in Food Preservation, Flavor and Safety; Elsevier: Amsterdam, The Netherlands, 2016; pp. 31-38.

13. Dhifi, W.; Bellili, S.; Jazi, S.; Bahloul, N.; Mnif, W. Essential Oils' Chemical Characterization and Investigation of Some Biological Activities: A Critical Review. Medicines 2016, 3, 25. [CrossRef]

14. Sharma, M.; Koul, A.; Sharma, D.; Kaul, S.; Swamy, M.K.; Dhar, M.K. Metabolic Engineering Strategies for Enhancing the Production of Bio-active Compounds from Medicinal Plants. In Natural Bio-Active Compounds; Springer: Berlin, Germany, 2019; pp. 287-316.

15. Pandey, A.K.; Kumar, P.; Singh, P.; Tripathi, N.N.; Bajpai, V.K. Essential Oils: Sources of Antimicrobials and Food Preservatives. Front. Microbiol. 2016, 7, 2161. [CrossRef] [PubMed]

16. Cava-Roda, R.M.; Taboada-Rodríguez, A.; Valverde-Franco, M.T.; Marín-Iniesta, F. Antimicrobial activity of vanillin and mixtures with cinnamon and clove essential oils in controlling Listeria monocytogenes and Escherichia coli O157: h7 in milk. Food Bioprocess. Technol. 2012, 5, 2120-2131. [CrossRef]

17. Alfonzo, A.; Martorana, A.; Guarrasi, V.; Barbera, M.; Gaglio, R.; Santulli, A.; Settanni, L.; Galati, A.; Moschetti, G.; Francesca, N. Effect of the lemon essential oils on the safety and sensory quality of salted sardines (Sardina pilchardus Walbaum 1792). Food Control 2017, 73, 1265-1274. [CrossRef]

18. Ojagh, S.M.; Rezaei, M.; Razavi, S.H.; hosseini, S.M.H. Effect of chitosan coatings enriched with cinnamon oil on the quality of refrigerated rainbow trout. Food Chem. 2010, 120, 193-198. [CrossRef]

19. Huang, Z.; Liu, X.; Jia, S.; Luo, Y. Antimicrobial effects of cinnamon bark oil on microbial composition and quality of grass carp (Ctenopharyngodon idellus) fillets during chilled storage. Food Control 2017, 82, 316-324. [CrossRef]

20. Miguel, M.G. Antioxidant and anti-inflammatory activities of essential oils: A short review. Molecules 2010, 15, 9252-9287. [CrossRef]

21. Anastasiou, C.; Buchbauer, G. Essential Oils as Immunomodulators: Some Examples. Open Chem. 2017, 15, 352-370. [CrossRef]

22. Chen, L.L.; Zhang, H.J.; Chao, J.; Liu, J.F. Essential oil of Artemisia argyi suppresses inflammatory responses by inhibiting JAK/STATs activation. J. Ethnopharmacol. 2017, 204, 107-117. [CrossRef]

23. Yang, C.; Zhang, L.; Cao, G.; Feng, J.; Yue, M.; Xu, Y.; Dai, B.; han, Q.; Guo, X. Effects of dietary supplementation with essential oils and organic acids on the growth performance, immune system, fecal volatile fatty acids, and microflora community in weaned piglets. J. Anim. Sci. 2019, 97, 133-143. [CrossRef]

24. Andrade, L.N.; De Sousa, D.P. A review on anti-inflammatory activity of monoterpenes. Molecules 2013, 18, 1227-1254. [CrossRef]

25. Aghraz, A.; Benameur, Q.; Gervasi, T.; Ait Dra, L.; Ben-Mahdi, M.; Larhsini, M.; Markouk, M.; Cicero, N. Antibacterial activity of Cladanthus arabicus and Bubonium imbricatum essential oils alone and in combination with conventional antibiotics against Enterobacteriaceae isolates. Lett. Appl. Microbiol. 2018, 67, 175-182. [CrossRef] [PubMed]

26. Alarcon, L.; Pena, A.; Velascd, J.; Baptista, J.G.; Rojas, L.; Aparicio, R.; Usubillaga, A. Chemical composition and antibacterial activity of the essential oil of Ruilopezia bracteosa. Nat. Prod. Commun. 2015, 10, 655-656. [CrossRef] [PubMed]

27. Ashraf, S.; Anjum, A.A.; Ahmad, A.; Firyal, S.; Sana, S.; Latif, A.A. In vitro activity of Nigella sativa against antibiotic resistant Salmonella enterica. Environ. Toxicol. Pharmacol. 2018, 58, 54-58. [CrossRef] [PubMed]

28. Alizadeh Behbahani, B.; Tabatabaei Yazdi, F.; Vasiee, A.; Mortazavi, S.A. Oliveria decumbens essential oil: Chemical compositions and antimicrobial activity against the growth of some clinical and standard strains causing infection. Microb. Pathog. 2018, 114, 449-452. [CrossRef] [PubMed] 
29. Boonyanugomol, W.; Kraisriwattana, K.; Rukseree, K.; Boonsam, K.; Narachai, P. In vitro synergistic antibacterial activity of the essential oil from Zingiber cassumunar Roxb against extensively drug-resistant Acinetobacter baumannii strains. J. Infect. Public health 2017, 10, 586-592. [CrossRef]

30. Chaib, F.; Allali, H.; Bennaceur, M.; Flamini, G. Chemical Composition and Antimicrobial Activity of Essential Oils from the Aerial Parts of Asteriscus graveolens (Forssk.) Less. and Pulicaria incisa (Lam.) DC.: Two Asteraceae herbs Growing Wild in the hoggar. Chem. Biodivers. 2017, 14, e1700092. [CrossRef]

31. Chen, C.C.; Yan, S.H.; Yen, M.Y.; Wu, P.F.; Liao, W.T.; huang, T.S.; Wen, Z.H.; Wang, H.M.D. Investigations of kanuka and manuka essential oils for in vitro treatment of disease and cellular inflammation caused by infectious microorganisms. J. Microbiol. Immunol. Infect. 2016, 49, 104-111. [CrossRef]

32. Chiboub, W.; Sassi, A.B.; Amina, C.M.; Souilem, F.; El Ayeb, A.; Djlassi, B.; Ascrizzi, R.; Flamini, G.; harzallah-Skhiri, F. Valorization of the Green Waste from Two Varieties of Fennel and Carrot Cultivated in Tunisia by Identification of the Phytochemical Profile and Evaluation of the Antimicrobial Activities of Their Essentials Oils. Chem. Biodivers. 2019, 16, e1800546. [CrossRef]

33. Condò, C.; Anacarso, I.; Sabia, C.; Iseppi, R.; Anfelli, I.; Forti, L.; de Niederhäusern, S.; Bondi, M.; Messi, P. Antimicrobial activity of spices essential oils and its effectiveness on mature biofilms of human pathogens. Nat. Prod. Res. 2018, 25, 1-8. [CrossRef]

34. de Jesus, I.C.; Santos Frazao, G.G.; Blank, A.F.; de Aquino Santana, L.C. Myrcia ovata Cambessedes essential oils: A proposal for a novel natural antimicrobial against foodborne bacteria. Microb. Pathog. 2016, 99, 142-147. [CrossRef]

35. Elshafie, H.S.; Sakr, S.; Mang, S.M.; Belviso, S.; De Feo, V.; Camele, I. Antimicrobial activity and chemical composition of three essential oils extracted from Mediterranean aromatic plants. J. Med. Food 2016, 19, 1096-1103. [CrossRef] [PubMed]

36. Fadil, M.; Fikri-Benbrahim, K.; Rachiq, S.; Ihssane, B.; Lebrazi, S.; Chraibi, M.; haloui, T.; Farah, A. Combined treatment of Thymus vulgaris L., Rosmarinus officinalis L. and Myrtus communis L. essential oils against Salmonella typhimurium: Optimization of antibacterial activity by mixture design methodology. Eur. J. Pharm. Biopharm. 2018, 126, 211-220. [CrossRef] [PubMed]

37. Falsafi, T.; Moradi, P.; Mahboubi, M.; Rahimi, E.; Momtaz, H.; hamedi, B. Chemical composition and anti-Helicobacter pylori effect of Satureja bachtiarica Bunge essential oil. Phytomedicine 2015, 22, 173-177. [CrossRef] [PubMed]

38. Fournomiti, M.; Kimbaris, A.; Mantzourani, I.; Plessas, S.; Theodoridou, I.; Papaemmanouil, V.; Kapsiotis, I.; Panopoulou, M.; Stavropoulou, E.; Bezirtzoglou, E.E.; et al. Antimicrobial activity of essential oils of cultivated oregano (Origanum vulgare), sage (Salvia officinalis), and thyme (Thymus vulgaris) against clinical isolates of Escherichia coli, Klebsiella oxytoca, and Klebsiella pneumoniae. Microb. Ecol. health Dis. 2015, 26, 23289. [CrossRef] [PubMed]

39. Gadisa, E.; Weldearegay, G.; Desta, K.; Tsegaye, G.; hailu, S.; Jote, K.; Takele, A. Combined antibacterial effect of essential oils from three most commonly used Ethiopian traditional medicinal plants on multidrug resistant bacteria. BMC Complement. Altern. Med. 2019, 19, 24. [CrossRef]

40. Igwaran, A.; Iweriebor, B.C.; Ofuzim Okoh, S.; Nwodo, U.U.; Obi, L.C.; Okoh, A.I. Chemical constituents, antibacterial and antioxidant properties of the essential oil flower of Tagetes minuta grown in Cala community Eastern Cape, South Africa. Bmc Complement. Altern. Med. 2017, 17, 351. [CrossRef] [PubMed]

41. Jaradat, N.; Adwan, L.; K'Aibni, S.; Shraim, N.; Zaid, A.N. Chemical composition, anthelmintic, antibacterial and antioxidant effects of Thymus bovei essential oil. Bmc Complement. Altern. Med. 2016, 16, 418. [CrossRef]

42. Lee, H.; Choi, H.; Lee, J.C.; Lee, Y.C.; Woo, E.R.; Lee, D.G. Antibacterial Activity of hibicuslide C on Multidrug-Resistant Pseudomonas aeruginosa Isolates. Curr. Microbiol. 2016, 73, 519-526. [CrossRef]

43. Linde, G.; Gazim, Z.; Cardoso, B.; Jorge, L.; Tešević, V.; Glamočlija, J.; Soković, M.; Colauto, N. Antifungal and antibacterial activities of Petroselinum crispum essential oil. Genet. Mol. Res. 2016. [CrossRef]

44. Mahmoudzadeh, M.; hosseini, H.; Nasrollahzadeh, J.; Khaneghah, A.M.; Rismanchi, M.; Chaves, R.D.; Shahraz, F.; Azizkhani, M.; Mahmoudzadeh, L.; haslberger, A.G. Antibacterial activity of Carum copticum essential oil against Escherichia coli O157: h7 in meat: Stx genes expression. Curr. Microbiol. 2016, 73, 265-272. [CrossRef]

45. Man, A.; Santacroce, L.; Jacob, R.; Mare, A.; Man, L. Antimicrobial Activity of Six Essential Oils Against a Group of human Pathogens: A Comparative Study. Pathogens 2019, 8, 15. [CrossRef] [PubMed] 
46. Marrelli, M.; Conforti, F.; Formisano, C.; Rigano, D.; Arnold, N.A.; Menichini, F.; Senatore, F. Composition, antibacterial, antioxidant and antiproliferative activities of essential oils from three Origanum species growing wild in Lebanon and Greece. Nat. Prod. Res. 2016, 30, 735-739. [CrossRef] [PubMed]

47. Meng, X.; Li, D.; Zhou, D.; Wang, D.; Liu, Q.; Fan, S. Chemical composition, antibacterial activity and related mechanism of the essential oil from the leaves of Juniperus rigida Sieb. et Zucc against Klebsiella pneumoniae. J. Ethnopharmacol. 2016, 194, 698-705. [CrossRef] [PubMed]

48. Montironi, I.D.; Cariddi, L.N.; Reinoso, E.B. Evaluation of the antimicrobial efficacy of Minthostachys verticillata essential oil and limonene against Streptococcus uberis strains isolated from bovine mastitis. Rev. Argent. Microbiol. 2016, 48, 210-216. [CrossRef] [PubMed]

49. Mutlu-Ingok, A.; Karbancioglu-Guler, F. Cardamom, Cumin, and Dill Weed Essential Oils: Chemical Compositions, Antimicrobial Activities, and Mechanisms of Action against Campylobacter spp. Molecules 2017, 22, 1191. [CrossRef] [PubMed]

50. Okoh, S.O.; Iweriebor, B.C.; Okoh, O.O.; Okoh, A.I. Bioactive constituents, radical scavenging, and antibacterial properties of the leaves and stem essential oils from Peperomia pellucida (L.) Kunth. Pharmacogn. Mag. 2017, 13, S392. [CrossRef] [PubMed]

51. Okoh, S.O.; Iweriebor, B.C.; Okoh, O.O.; Nwodo, U.U.; Okoh, A.I. Antibacterial and Antioxidant Properties of the Leaves and Stem Essential Oils of Jatropha gossypifolia L. Biomed Res. Int. 2016, 2016, 9392716. [CrossRef]

52. Oukerrou, M.A.; Tilaoui, M.; Mouse, H.A.; Leouifoudi, I.; Jaafari, A.; Zyad, A. Chemical composition and cytotoxic and antibacterial activities of the essential oil of Aloysia citriodora palau grown in Morocco. Adv. Pharmacol. Sci. 2017, 2017, 1-10. [CrossRef]

53. Paredes, A.; Leyton, Y.; Riquelme, C.; Morales, G. A plant from the altiplano of Northern Chile Senecio nutans, inhibits the Vibrio cholerae pathogen. SpringerPlus 2016, 5, 1788. [CrossRef]

54. Patra, J.; Baek, K.-H. Antibacterial activity and action mechanism of the essential oil from Enteromorpha linza L. against foodborne pathogenic bacteria. Molecules 2016, 21, 388. [CrossRef]

55. Pereira, C.A.; Costa, A.C.; Liporoni, P.C.; Rego, M.A.; Jorge, A.O. Antibacterial activity of Baccharis dracunculifolia in planktonic cultures and biofilms of Streptococcus mutans. J. Infect. Public health 2016, 9, 324-330. [CrossRef] [PubMed]

56. Porfírio, E.M.; Melo, H.M.; Pereira, A.M.G.; Cavalcante, T.T.A.; Gomes, G.A.; Carvalho, M.G.D.; Costa, R.A.; Júnior, F.E.A.C. In vitro antibacterial and antibiofilm activity of Lippia alba essential oil, citral, and carvone against Staphylococcus aureus. Sci. World J. 2017, 2017, 1-7. [CrossRef] [PubMed]

57. Puškárová, A.; Bučková, M.; Kraková, L.; Pangallo, D.; Kozics, K. The antibacterial and antifungal activity of six essential oils and their cyto/genotoxicity to human hEL 12469 cells. Sci. Rep. 2017, 7, 8211. [CrossRef] [PubMed]

58. Sakkas, H.; Gousia, P.; Economou, V.; Sakkas, V.; Petsios, S.; Papadopoulou, C. In vitro antimicrobial activity of five essential oils on multidrug resistant Gram-negative clinical isolates. J. Intercult. Ethnopharmacol. 2016, 5, 212. [CrossRef]

59. Salem, M.Z.; Elansary, H.O.; Ali, H.M.; El-Settawy, A.A.; Elshikh, M.S.; Abdel-Salam, E.M.; Skalicka-Woźniak, K. Bioactivity of essential oils extracted from Cupressus macrocarpa branchlets and Corymbia citriodora leaves grown in Egypt. Bmc Complement. Altern. Med. 2018, 18, 23. [CrossRef]

60. Semeniuc, C.A.; Pop, C.R.; Rotar, A.M. Antibacterial activity and interactions of plant essential oil combinations against Gram-positive and Gram-negative bacteria. J. Food Drug Anal. 2017, 25, 403-408. [CrossRef]

61. Sharafati Chaleshtori, F.; Saholi, M.; Sharafati Chaleshtori, R. Chemical Composition, Antioxidant and Antibacterial Activity of Bunium persicum, Eucalyptus globulus, and Rose Water on Multidrug-Resistant Listeria Species. J. Evid.-Based Integr. Med. 2018, 23, 2515690X17751314. [CrossRef]

62. Sharifi, A.; Mohammadzadeh, A.; Salehi, T.Z.; Mahmoodi, P. Antibacterial, antibiofilm and antiquorum sensing effects of Thymus daenensis and Satureja hortensis essential oils against Staphylococcus aureus isolates. J. Appl. Microbiol. 2018, 124, 379-388. [CrossRef]

63. Sharifi-Rad, J.; hoseini-Alfatemi, S.; Sharifi-Rad, M.; Sharifi-Rad, M.; Iriti, M.; Sharifi-Rad, M.; Sharifi-Rad, R.; Raeisi, S. Phytochemical compositions and biological activities of essential oil from Xanthium strumarium L. Molecules 2015, 20, 7034-7047. [CrossRef] 
64. Smeriglio, A.; Denaro, M.; Barreca, D.; Calderaro, A.; Bisignano, C.; Ginestra, G.; Bellocco, E.; Trombetta, D. In Vitro Evaluation of the Antioxidant, Cytoprotective, and Antimicrobial Properties of Essential Oil from Pistacia vera L. Variety Bronte hull. Int. J. Mol. Sci. 2017, 18, 1212. [CrossRef]

65. Snoussi, M.; Dehmani, A.; Noumi, E.; Flamini, G.; Papetti, A. Chemical composition and antibiofilm activity of Petroselinum crispum and Ocimum basilicum essential oils against Vibrio spp. strains. Microb. Pathog. 2016, 90, 13-21. [CrossRef] [PubMed]

66. Soliman, S.S.M.; Alsaadi, A.I.; Youssef, E.G.; Khitrov, G.; Noreddin, A.M.; husseiny, M.I.; Ibrahim, A.S. Calli Essential Oils Synergize with Lawsone against Multidrug Resistant Pathogens. Molecules 2017, 22, 2223. [CrossRef] [PubMed]

67. Tibyangye, J.; Okech, M.A.; Nyabayo, J.M.; Nakavuma, J.L. In vitro antibacterial activity of Ocimum suave essential oils against uropathogens isolated from patients in selected hospitals in Bushenyi district, Uganda. Br. Microbiol. Res. J. 2015, 8, 489. [CrossRef] [PubMed]

68. Touihri, I.; Boukhris, M.; Marrakchi, N.; Luis, J.; hanchi, B.; Kallech-Ziri, O. Chemical Composition and Biological Activities of Allium roseum L. var. grandiflorum Briq. Essential Oil. J. Oleo Sci. 2015, 2015, ess15055. [CrossRef] [PubMed]

69. Ušjak, L.; Petrović, S.; Drobac, M.; Soković, M.; Stanojković, T.; Ćirić, A.; Niketić, M. Edible wild plant heracleum pyrenaicum subsp. orsinii as a potential new source of bioactive essential oils. J. Food Sci. Technol. 2017, 54, 2193-2202. [CrossRef] [PubMed]

70. Utegenova, G.A.; Pallister, K.B.; Kushnarenko, S.V.; Ozek, G.; Ozek, T.; Abidkulova, K.T.; Kirpotina, L.N.; Schepetkin, I.A.; Quinn, M.T.; Voyich, J.M. Chemical Composition and Antibacterial Activity of Essential Oils from Ferula L. Species against Methicillin-Resistant Staphylococcus aureus. Molecules 2018, 23, 1679. [CrossRef]

71. Vieira, M.; Bessa, L.J.; Martins, M.R.; Arantes, S.; Teixeira, A.P.; Mendes, A.; Martins da Costa, P.; Belo, A.D. Chemical composition, antibacterial, antibiofilm and synergistic properties of essential oils from Eucalyptus globulus Labill. and seven Mediterranean aromatic plants. Chem. Biodivers. 2017, 14, e1700006. [CrossRef]

72. Xu, J.-G.; Liu, T.; hu, Q.-P.; Cao, X.-M. Chemical composition, antibacterial properties and mechanism of action of essential oil from clove buds against Staphylococcus aureus. Molecules 2016, 21, 1194. [CrossRef]

73. Zhao, J.; Jiang, L.; Tang, X.; Peng, L.; Li, X.; Zhao, G.; Zhong, L. Chemical Composition, Antimicrobial and Antioxidant Activities of the Flower Volatile Oils of Fagopyrum esculentum, Fagopyrum tataricum and Fagopyrum Cymosum. Molecules 2018, 23, 182. [CrossRef]

74. Bag, A.; Chattopadhyay, R.R. Evaluation of Synergistic Antibacterial and Antioxidant Efficacy of Essential Oils of Spices and herbs in Combination. PLOS ONE 2015, 10, e0131321. [CrossRef]

75. Djenane, D. Chemical Profile, Antibacterial and Antioxidant Activity of Algerian Citrus Essential Oils and Their Application in Sardina pilchardus. Foods 2015, 4, 208-228. [CrossRef] [PubMed]

76. Ehsani, A.; Alizadeh, O.; hashemi, M.; Afshari, A.; Aminzare, M. Phytochemical, antioxidant and antibacterial properties of Melissa officinalis and Dracocephalum moldavica essential oils. Vet. Res. Forum 2017, 8, 223-229. [PubMed]

77. Hu, Q.P.; Cao, X.M.; hao, D.L.; Zhang, L.L. Chemical Composition, Antioxidant, DNA Damage Protective, Cytotoxic and Antibacterial Activities of Cyperus rotundus Rhizomes Essential Oil against Foodborne Pathogens. Sci. Rep. 2017, 7, 45231. [CrossRef] [PubMed]

78. Jaradat, N.; Adwan, L.; K'Aibni, S.; Zaid, A.N.; Shtaya, M.J.Y.; Shraim, N.; Assali, M. Variability of Chemical Compositions and Antimicrobial and Antioxidant Activities of Ruta chalepensis Leaf Essential Oils from Three Palestinian Regions. Biomed Res. Int. 2017, 2017, 2672689. [CrossRef] [PubMed]

79. Kazemi, M. Chemical composition and antimicrobial, antioxidant activities and anti-inflammatory potential of Achillea millefolium L., Anethum graveolens L., and Carum copticum L. essential oils. J. herb. Med. 2015, 5, 217-222. [CrossRef]

80. Marin, I.; Sayas-Barbera, E.; Viuda-Martos, M.; Navarro, C.; Sendra, E. Chemical Composition, Antioxidant and Antimicrobial Activity of Essential Oils from Organic Fennel, Parsley, and Lavender from Spain. Foods 2016, 5, 18. [CrossRef]

81. Marrelli, M.; Araniti, F.; Abenavoli, M.R.; Statti, G.; Conforti, F. Potential health Benefits of Origanum heracleoticum Essential Oil: Phytochemical and Biological Variability among Different Calabrian Populations. Nat. Prod. Commun. 2018, 13. [CrossRef] 
82. Okoh, S.O.; Iweriegbor, B.C.; Okoh, O.O.; Nwodo, U.U.; Okoh, A.I. Bactericidal and antioxidant properties of essential oils from the fruits Dennettia tripetala G. Baker. BMC Complement. Altern. Med. 2016, 16, 486. [CrossRef]

83. Ouedrhiri, W.; Balouiri, M.; Bouhdid, S.; harki, E.H.; Moja, S.; Greche, H. Antioxidant and antibacterial activities of Pelargonium asperum and Ormenis mixta essential oils and their synergistic antibacterial effect. Environ. Sci. Pollut. Res. Int. 2018, 25, 29860-29867. [CrossRef]

84. Ghasemi Pirbalouti, A.; Izadi, A.; Malek Poor, F.; hamedi, B. Chemical composition, antioxidant and antibacterial activities of essential oils from Ferulago angulata. Pharm. Biol. 2016, 54, 2515-2520. [CrossRef]

85. Poaty, B.; Lahlah, J.; Porqueres, F.; Bouafif, H. Composition, antimicrobial and antioxidant activities of seven essential oils from the North American boreal forest. World J. Microbiol. Biotechnol. 2015, 31, 907-919. [CrossRef] [PubMed]

86. Semeniuc, C.A.; Socaciu, M.I.; Socaci, S.A.; Muresan, V.; Fogarasi, M.; Rotar, A.M. Chemometric Comparison and Classification of Some Essential Oils Extracted from Plants Belonging to Apiaceae and Lamiaceae Families Based on Their Chemical Composition and Biological Activities. Molecules 2018, 23, 2261. [CrossRef] [PubMed]

87. Shakeri, A.; Akhtari, J.; Soheili, V.; Taghizadeh, S.F.; Sahebkar, A.; Shaddel, R.; Asili, J. Identification and biological activity of the volatile compounds of Glycyrrhiza triphylla Fisch. \& C.A.Mey. Microb. Pathog. 2017, 109, 39-44. [CrossRef] [PubMed]

88. Snoussi, M.; Noumi, E.; Trabelsi, N.; Flamini, G.; Papetti, A.; De Feo, V. Mentha spicata Essential Oil: Chemical Composition, Antioxidant and Antibacterial Activities against Planktonic and Biofilm Cultures of Vibrio spp. Strains. Molecules 2015, 20, 14402-14424. [CrossRef]

89. Chen, H.C.; Chang, W.T.; hseu, Y.C.; Chen, H.Y.; Chuang, C.H.; Lin, C.C.; Lee, M.S.; Lin, M.K. Immunosuppressive Effect of Litsea cubeba L. Essential Oil on Dendritic Cell and Contact hypersensitivity Responses. Int. J. Mol. Sci. 2016, 17, 1319. [CrossRef]

90. Cheng, C.; Zou, Y.; Peng, J. Oregano Essential Oil Attenuates RAW264.7 Cells from Lipopolysaccharide-Induced Inflammatory Response through Regulating NADPH Oxidase Activation-Driven Oxidative Stress. Molecules 2018, 23, 1857. [CrossRef]

91. Krifa, M.; El Mekdad,H.; Bentouati, N.; Pizzi, A.; Ghedira, K.; hammami, M.; El Meshri, S.E.; Chekir-Ghedira, L. Immunomodulatory and anticancer effects of Pituranthos tortuosus essential oil. Tumour Biol. 2015, 36, 5165-5170. [CrossRef]

92. Ma, Q.; Jiang, J.G.; Yuan, X.; Qiu, K.; Zhu, W. Comparative antitumor and anti-inflammatory effects of flavonoids, saponins, polysaccharides, essential oil, coumarin and alkaloids from Cirsium japonicum DC. Food Chem. Toxicol. 2019, 125, 422-429. [CrossRef]

93. Oüzek, G.; Schepetkin, I.A.; Utegenova, G.A.; Kirpotina, L.N.; Andrei, S.R.; Oüzek, T.; Baser, K.H.C.; Abidkulova, K.T.; Kushnarenko, S.V.; Khlebnikov, A.I.; et al. Chemical composition and phagocyte immunomodulatory activity of Ferula iliensis essential oils. J. Leukoc. Biol. 2017, 101, 1361-1371. [CrossRef]

94. Park, Y.; Yoo, S.-A.; Kim, W.-U.; Cho, C.-S.; Woo, J.-M.; Yoon, C.-H.; Yoo, S.; Kim, W.; Cho, C.; Woo, J.; et al. Anti-inflammatory effects of essential oils extracted from Chamaecyparis obtusa on murine models of inflammation and RAW 264.7 cells. Mol. Med. Rep. 2016, 13, 3335-3341. [CrossRef]

95. Wang, Y.-T.; Zhu, L.; Zeng, D.; Long, W.; Zhu, S.-M. Chemical composition and anti-inflammatory activities of essential oil from Trachydium roylei. J. Food Drug Anal. 2016, 24, 602-609. [CrossRef] [PubMed]

96. Adaszyńska-Skwirzyńska, M.; Szczerbińska, D. The effect of lavender (Lavandula angustifolia) essential oil as a drinking water supplement on the production performance, blood biochemical parameters, and ileal microflora in broiler chickens. Poult. Sci. 2018, 98, 358-365. [CrossRef] [PubMed]

97. Altop, A.; Erener, G.; Duru, M.E.; Isik, K. Effects of essential oils from Liquidambar orientalis Mill. leaves on growth performance, carcass and some organ traits, some blood metabolites and intestinal microbiota in broilers. Br. Poult. Sci. 2018, 59, 121-127. [CrossRef] [PubMed]

98. Cetin, E.; Yibar, A.; Yesilbag, D.; Cetin, I.; Cengiz, S.S. The effect of volatile oil mixtures on the performance and ilio-caecal microflora of broiler chickens. Br. Poult. Sci. 2016, 57, 780-787. [CrossRef] [PubMed]

99. Cairo, P.L.G.; Gois, F.D.; Sbardella, M.; Silveira, H.; de Oliveira, R.M.; Allaman, I.B.; Cantarelli, V.S.; Costa, L.B. Effects of dietary supplementation of red pepper (Schinus terebinthifolius Raddi) essential oil on performance, small intestinal morphology and microbial counts of weanling pigs. J. Sci. Food Agric. 2018, 98, 541-548. [CrossRef] [PubMed] 
100. Li, Y.; Fu, X.; Ma, X.; Geng, S.; Jiang, X.; huang, Q.; hu, C.; han, X. Intestinal Microbiome-Metabolome Responses to Essential Oils in Piglets. Front. Microbiol. 2018, 9, 1988. [CrossRef] [PubMed]

101. Silva, L.D.L.; Baldisserotto, B.; Sutili, F.; Gressler, L.; Battisti, E.; heinzmann, B.; De Vargas, A.C. Plant essential oils against Aeromonas hydrophila: In vitro activity and their use in experimentally infected fish. J. Appl. Microbiol. 2015, 119, 47-54. [CrossRef]

102. Sell, C.S. The Chemistry of Fragrances: From Perfumer to Consumer; Royal Society of Chemistry: London, UK, 2006; Volume 38.

103. Balouiri, M.; Sadiki, M.; Ibnsouda, S.K. Methods for in vitro evaluating antimicrobial activity: A review. J. Pharm. Anal. 2016, 6, 71-79. [CrossRef]

104. Coughlan, L.M.; Cotter, P.D.; hill, C.; Alvarez-Ordóñez, A. New Weapons to Fight Old Enemies: Novel Strategies for the (Bio)control of Bacterial Biofilms in the Food Industry. Front. Microbiol. 2016, 7, 1641. [CrossRef]

105. Winkelstroter, L.K.; Teixeira, F.B.; Silva, E.P.; Alves, V.F.; De Martinis, E.C. Unraveling microbial biofilms of importance for food microbiology. Microb. Ecol. 2014, 68, 35-46. [CrossRef]

106. Li, Y.-H.; Tian, X. Quorum Sensing and Bacterial Social Interactions in Biofilms. Sensors 2012, 12, $2519-2538$. [CrossRef]

107. Finkel, T. Oxidant signals and oxidative stress. Curr. Opin. Cell Biol. 2003, 15, 247-254. [CrossRef]

108. Hadi, S.; Bhat, S.; Azmi, A.; hanif, S.; Shamim, U.; Ullah, M. Oxidative breakage of cellular DNA by plant polyphenols: A putative mechanism for anticancer properties. Semin. Cancer Biol. 2007, 17, 370-376. [CrossRef] [PubMed]

109. Lanciotti, R.; Gianotti, A.; Patrignani, F.; Belletti, N.; Guerzoni, M.; Gardini, F. Use of natural aroma compounds to improve shelf-life and safety of minimally processed fruits. Trends Food Sci. Technol. 2004, 15, 201-208. [CrossRef]

110. Tenore, G.C.; Ciampaglia, R.; Arnold, N.A.; Piozzi, F.; Napolitano, F.; Rigano, D.; Senatore, F. Antimicrobial and antioxidant properties of the essential oil of Salvia lanigera from Cyprus. Food Chem. Toxicol. 2011, 49, 238-243. [CrossRef]

111. de Lavor, É.M.; Fernandes, A.W.C.; de Andrade Teles, R.B.; Leal, A.E.B.P.; de Oliveira Júnior, R.G.; Gama e Silva, M.; de Oliveira, A.P.; Silva, J.C.; de Moura Fontes Araújo, M.T.; Coutinho, H.D.M.; et al. Essential Oils and Their Major Compounds in the Treatment of Chronic Inflammation: A Review of Antioxidant Potential in Preclinical Studies and Molecular Mechanisms. Oxidative Med. Cell. Longev. 2018, 2018, 6468593. [CrossRef]

112. Thapa, D.; Louis, P.; Losa, R.; Zweifel, B.; Wallace, R.J. Essential oils have different effects on human pathogenic and commensal bacteria in mixed faecal fermentations compared with pure cultures. Microbiology 2015, 161, 441-449. [CrossRef]

(C) 2019 by the authors. Licensee MDPI, Basel, Switzerland. This article is an open access article distributed under the terms and conditions of the Creative Commons Attribution (CC BY) license (http://creativecommons.org/licenses/by/4.0/). 